\title{
Widely Conserved Attenuation of Plant MAMP-Induced Calcium Influx by Bacteria Depends on Multiple Virulence Factors and May Involve Desensitization of Host Pattern Recognition Receptors
}

\author{
Meltem Lammertz, ${ }^{1}$ Hannah Kuhn, ${ }^{1}$ Sebastian Pfeilmeier, ${ }^{2,3}$ Jacob Malone, ${ }^{2,4}$ Cyril Zipfel, ${ }^{3}$ \\ Mark Kwaaitaal, ${ }^{1}$ Nai-Chun Lin, ${ }^{5}$ Brian H. Kvitko, ${ }^{6}$ and Ralph Panstruga ${ }^{1}$ \\ ${ }^{1}$ Unit of Plant Molecular Cell Biology, Institute for Biology I, RWTH Aachen University, 52074 Aachen, Germany; ${ }^{2}$ John Innes \\ Centre, Norwich Research Park, Norwich NR4 7UH, U.K.; ${ }^{3}$ The Sainsbury Laboratory, Norwich Research Park, Norwich NR4 \\ 7UH, U.K.; ${ }^{4}$ University of East Anglia, Norwich Research Park, Norwich NR4 7TJ, U.K.; ${ }^{5}$ Department of Agricultural Chemistry, \\ National Taiwan University, Taipei 106, Taiwan, Republic of China; and ${ }^{6}$ Department of Plant Pathology, University of Georgia, \\ Athens, GA 30602, U.S.A.
}

Accepted 14 November 2018.

Successful pathogens must efficiently defeat or delay host immune responses, including those triggered by release or exposure of microbe-associated molecular patterns (MAMPs). Knowledge of the molecular details leading to this phenomenon in genuine plant-pathogen interactions is still scarce. We took advantage of the well-established Arabidopsis thaliana-Pseudomonas syringae pv. tomato DC3000 pathosystem to explore the molecular prerequisites for the suppression of MAMP-triggered host defense by the bacterial invader. Using a transgenic Arabidopsis line expressing the calcium sensor apoaequorin, we discovered that strain DC3000 colonization results in a complete inhibition of MAMP-induced cytosolic

M. Lammertz and H. Kuhn contributed equally to the work.

Current address for S. Pfeilmeier: Institute of Microbiology, Department of Biology, ETH Zurich, 8093 Zurich, Switzerland.

Current address for C. Zipfel: Institute of Plant and Microbial Biology, Zurich-Basel Plant Science Center, University of Zurich, 8008 Zurich, Switzerland.

Corresponding author: R. Panstruga;

E-mail: panstruga@bio1.rwth-aachen.de

Funding: Work in the laboratory of R. Panstruga is supported by RWTH Aachen University core funds. This study was additionally supported by the Excellence Initiative of the German federal and state governments (Seed Fund provided to R. Panstruga by RWTH Aachen University and Diversity Fund provided to M. Lammertz by RWTH Aachen University), which is administrated by the Deutsche Forschungsgemeinschaft. S. Pfeilmeier was funded by a studentship from the Norwich Research Park. Research in the J. Malone and C. Zipfel laboratories is supported by the Biotechnology and Biological Sciences Research Council Institute Strategic Program Grant BB/J004553/1. The C. Zipfel laboratory is further supported by the Gatsby Charitable Foundation.

*The $\boldsymbol{e}$-Xtra logo stands for "electronic extra" and indicates that one supplementary table and eight supplementary figures are published online.

The author(s) declare no conflict of interest.

Modified: 21 Jan 2022.

() 2019 The American Phytopathological Society calcium influx, a key event of immediate-early host immune signaling. A range of further plant-associated bacterial species is also able to prevent, either partially or fully, the MAMPtriggered cytosolic calcium pattern. Genetic analysis revealed that this suppressive effect partially relies on the bacterial type III secretion system (T3SS) but cannot be attributed to individual members of the currently known arsenal of strain DC3000 effector proteins. Although the phytotoxin coronatine and bacterial flagellin individually are dispensable for the effective inhibition of MAMP-induced calcium signatures, they contribute to the attenuation of calcium influx in the absence of the T3SS. Our findings suggest that the capacity to interfere with early plant immune responses is a widespread ability among plant-associated bacteria that, at least in strain DC3000, requires the combinatorial effect of multiple virulence determinants. This may also include the desensitization of host pattern recognition receptors by the prolonged exposure to MAMPs during bacterial pathogenesis.

The bacterial phytopathogen Pseudomonas syringae pv. tomato DC3000 is the causal agent of the bacterial speck disease of tomato (Solanum lycopersicum) and thale cress (Arabidopsis thaliana). First described in 1986 (Cuppels 1986), P. syringae pv. tomato strain DC3000 rapidly emerged as a model organism to study the molecular principles underlying bacterial virulence and host immunity (Xin and He 2013). The availability of ample genetic resources renders this pathogen exquisitely suited to explore the molecular pathways required for bacterial pathogenesis and plant resistance.

$P$. syringae pv. tomato DC3000 colonizes the intercellular spaces in leaves and other aerial organs. To defeat plant innate immunity, the pathogen injects effector proteins into host cells via the type-III secretion system (T3SS), which often is described as a molecular syringe ("injectisome") (Erhardt et al. 2010). In strain DC3000, the T3SS is encoded by hypersensitive response and pathogenicity (hrp) and hypersensitive response and conserved (hrc) genes, and the effectors are accordingly designated as Hrp outer proteins (Hop) or, when inducing an avirulence reaction in the plant host, avirulence (Avr) proteins (Lindeberg et al. 2005). More than half of the effector genes known to encode fully active protein effectors (at least 28) 
are organized in five genomic clusters and a conserved effector locus (CEL), which is considered as the sixth cluster (Cunnac et al. 2009; Kvitko et al. 2009). In addition to T3SSdependent effector genes grouped in clusters, at least 10 further effector genes are individually dispersed throughout the strain DC3000 genome (Kvitko et al. 2009).

In general, bacterial effector proteins act transcriptionally and posttranscriptionally to suppress plant immunity, including microbe-associated molecular pattern (MAMP)-triggered responses (de Torres et al. 2006; Hauck et al. 2003). Although great progress regarding the elucidation of effector functions has been achieved during the past decade, the biochemical activity of many $P$. syringae pv. tomato DC3000 effectors remains elusive (Cunnac et al. 2009). However, for some key effectors, the mode of action has been deciphered. These include, for example, AvrPto and AvrPtoB, which were initially discovered based on their avirulence function in tomato (Kim et al. 2002; Scofield et al. 1996). AvrPto binds to and inhibits the autophosphorylation of plasma membrane-localized pattern recognition receptors (PRRs) that play a key role in the perception of MAMPs and the initiation of immune responses, thereby abolishing their function (Xiang et al. 2008). AvrPtoB has E3 ubiquitin ligase activity and targets several PRRs, including the flagellin receptor FLAGELLIN SENSING2 (FLS2) and the oligosaccharide coreceptor CHITIN ELICITOR RE-CEPTOR KINASE1 (CERK1), for proteolytic removal via the 26S proteasome (Gimenez-Ibanez et al. 2009; Göhre et al. 2008; Janjusevic et al. 2006). In addition, AvrPtoB dissociates the common PRR coreceptor BRASSINOSTEROID INSENSITIVE1associated receptor kinase 1 (BAK1) from MAMP receptor complexes (Shan et al. 2008). Consistent with their role in suppression of plant immunity, strain DC3000 mutants defective in AvrPto and AvrPtoB show reduced virulence in tomato plants deficient of the Pto kinase (Lin and Martin 2005) and in Arabidopsis (Macho et al. 2007).

In addition to proteinaceous effectors, which are predominantly delivered via the T3SS, nonproteinaceous molecules contribute to bacterial virulence. One class of such compounds comprises secreted bacterial secondary metabolites that enhance virulence, which are sometimes also referred to as phytotoxins (Bender et al. 1999). One of the best-studied secreted secondary metabolites is the nonhost-specific phytotoxin coronatine, which is produced by several pathovars of $P$. syringae, including DC3000 (Moore et al. 1989). Coronatine is known to reopen closed stomata to promote bacterial entry and to activate the jasmonic acid signaling pathway in Arabidopsis and tomato (Bender et al. 1999; Melotto et al. 2006). P. syringae pv. tomato DC3000 $\Delta c f a$ and $\Delta c m a$ mutants, which are deficient in the biosynthesis of coronafacic acid and coronamic acid, the two coronatine precursors, show severely attenuated virulence on Arabidopsis and tomato leaves (Brooks et al. 2004; Melotto et al. 2008).

Another major class of compounds that may contribute to bacterial virulence are secreted surface molecules such as extracellular polysaccharides (exopolysaccharides [EPSs]). EPSs have been described as virulence factors of bacteria infecting animals or humans (Vuong et al. 2004) and plants (Denny 1995). In the case of strain DC3000, it was demonstrated that these polyanionic molecules (in particular, alginate) suppress MAMP-based immunity by chelating extracellular calcium $\left(\mathrm{Ca}^{2+}\right)$ ions (Aslam et al. 2008). Influx of $\mathrm{Ca}^{2+}$ from the apoplastic space into the cytosol is known as an immediate-early response during MAMP signaling (Blume et al. 2000; Jeworutzki et al. 2010; Lecourieux et al. 2006). Thus, interference with MAMP-induced $\mathrm{Ca}^{2+}$ influx by bacterial EPSs is a potentially potent way to block plant innate immunity (Aslam et al. 2008).

Exogenous application of MAMPs to plant organs (leaves) or plant cells triggers a characteristic pattern of $\mathrm{Ca}^{2+}$ influx that can be visualized by suitable $\mathrm{Ca}^{2+}$ reporter systems. Transgenic Arabidopsis lines expressing the heterologous apoprotein aequorin allow visualization of MAMP-induced $\mathrm{Ca}^{2+}$ signatures at the tissue or whole-seedling level (Aslam et al. 2009; Knight et al. 1991). Although defense suppression by phytopathogens is a well-established phenomenon in plant-microbe interactions, many molecular details of this process remain to be explored. Monitoring $\mathrm{Ca}^{2+}$ signatures is an exquisite means to study this feature because $\mathrm{Ca}^{2+}$ influx is an immediate-early MAMP-triggered immune response that can be readily measured and quantified in a noninvasive manner.

Here, we used a hydroponic culture system to study the effect of defense suppression by $P$. syringae pv. tomato DC3000, choosing cytosolic MAMP-induced $\mathrm{Ca}^{2+}$ influx as a proxy for early plant immunity. Transgenic, apoaequorinexpressing Arabidopsis seedlings were first challenged with strain DC3000, and a MAMP response was triggered subsequently. This experimental setup revealed near-complete attenuation of MAMP-triggered cytosolic $\mathrm{Ca}^{2+}$ influx by the bacteria. A comprehensive collection of strain DC3000 mutants was deployed to decipher the molecular basis of this phenomenon, which revealed a partial and cooperative contribution of the T3SS, coronatine, and flagellin to the phenotype.

\section{RESULTS}

To study whether phytopathogenic bacteria are able to suppress canonical MAMP-induced $\mathrm{Ca}^{2+}$ signatures, we used an experimental setup based on a 96-well liquid culture system. We inoculated 10- to 14-day-old hydroponically grown, apoaequorin-expressing Arabidopsis seedlings (a transgenic Col-0 P35S::apoaequorin line) (Knight et al. 1991) with virulent $P$. syringae pv. tomato DC3000, which essentially resembles infection of soil-grown plants with regard to pathogen proliferation (Supplementary Fig. S1) (Faulkner et al. 2013). At various time points after inoculation $(12,24,36$, and $48 \mathrm{~h}$ postinoculation [hpi]), we triggered a MAMP response by adding the flagellin-derived flg22 peptide $(1 \mu \mathrm{M})$ to the growth medium. Immediately after MAMP addition, we recorded alterations in cytosolic $\mathrm{Ca}^{2+}$ levels $\left(\left[\mathrm{Ca}^{2+}\right]_{\text {cyt }}\right)$ by measuring aequorin-derived luminescence over a period of $45 \mathrm{~min}$ in a microplate luminometer. This experimental design, comprising inoculation and a subsequent MAMP stimulus, allowed us to unravel whether strain DC3000 bacteria were able to interfere with a canonical MAMP response in the course of the genuine infection process.

Mock-inoculated Col-0 (P35S::apoaequorin) control seedlings showed at all time points the characteristic flg22-induced transient increase of $\left[\mathrm{Ca}^{2+}\right]_{\text {cyt }}$ with a maximum $\Delta\left[\mathrm{Ca}^{2+}\right]_{\text {cyt }}$ of approximately 70 to $90 \mathrm{nM}$ (Aslam et al. 2009), while $P$. syringae pv. tomato DC3000-inoculated seedlings revealed a gradual attenuation of this response over time. Whereas, at $12 \mathrm{hpi}$, the $\Delta\left[\mathrm{Ca}^{2+}\right]_{\mathrm{cyt}}$ of control and strain DC3000-challenged seedlings was undistinguishable, we noted an evident reduction in $\Delta\left[\mathrm{Ca}^{2+}\right]_{\text {cyt }}$ at $24 \mathrm{hpi}$ and a near-complete absence of any flg22-induced $\mathrm{Ca}^{2+}$ transient in Col- 0 bacteria-treated seedlings at 36 and 48 hpi (Fig. 1A). We quantified this effect by determining the respective areas under the curve (AUCs) of data from multiple independent experiments, focusing on 24 and 48 hpi as characteristic early and late time points, respectively, after inoculation. In relation to mock-inoculated control seedlings set as $100 \%$ AUC, strain DC3000-inoculated seedlings showed a reduction to approximately $40 \%$ AUC at $24 \mathrm{hpi}$ and approximately $10 \%$ AUC at $48 \mathrm{hpi}$ (Fig. 1B). This effect depends on the bacterial titer used as a start inoculum because, at optical densities at $600 \mathrm{~nm}\left(\mathrm{OD}_{600}\right)$ of $10^{-7}$ and $10^{-8}$, the reduction of $\Delta\left[\mathrm{Ca}^{2+}\right]_{\mathrm{cyt}}$ was partially or fully relieved, 
respectively (Supplementary Fig. S2). Lack of intensive trypan blue staining in both mock-treated and inoculated seedlings at 48 hpi excludes the possibility that an impaired viability of strain DC3000-inoculated seedlings is responsible for the abrogated flg22-triggered $\mathrm{Ca}^{2+}$ influx.

To explore whether the observed phenomenon is confined to the bacterial peptide MAMP flg22, we performed the same assay as described above but used either the bacterial ELONGATION FACTOR-THERMO UNSTABLE-derived peptide MAMP elf18 $(1 \mu \mathrm{M})$ or the fungal polycarbohydrate MAMP chitin $(0.1 \mathrm{mg} / \mathrm{ml})$ as inducers. We noted a similar outcome as observed for flg22, with an intermediate reduction of the $\mathrm{Ca}^{2+}$ transient at 24 hpi (approximately 40 and 50\% AUC for elf 18 and chitin, respectively) and a more pronounced decline of the $\mathrm{Ca}^{2+}$ transient at 48 hpi (approximately 10 and 30\% AUC for elf18 and chitin, respectively) (Fig. 1B). We further broadened our approach and tested two non-MAMPs as triggers of a cytoplasmic $\mathrm{Ca}^{2+}$ signature: the defense-associated phytohormone salicylic acid (SA; $1 \mathrm{mM}$ ) and the osmotically active polyol,
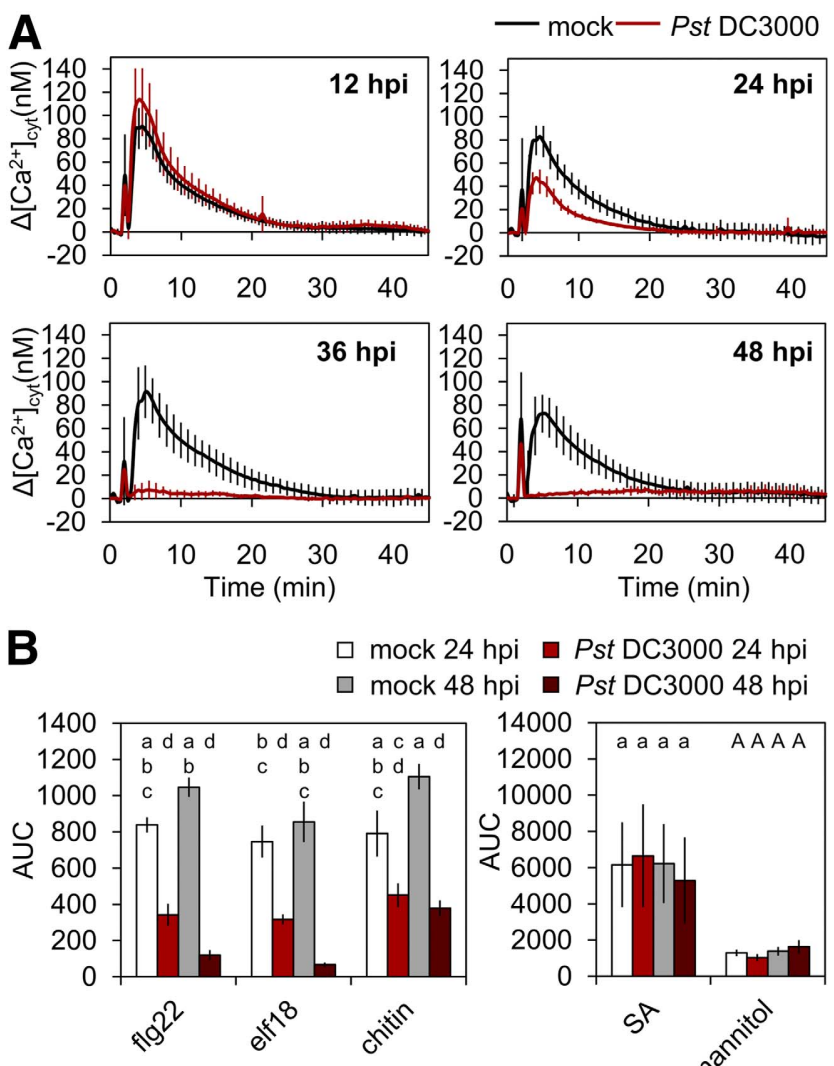

mock $24 \mathrm{hpi} \square$ Pst DC3000 $24 \mathrm{hpi}$

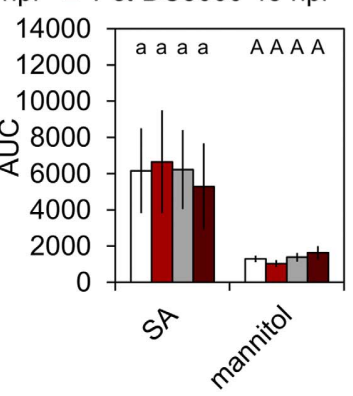

Fig. 1. Pseudomonas syringae pv. tomato DC3000 attenuates microbeassociated molecular pattern- but not salicylic acid (SA)- or mannitol-triggered $\mathrm{Ca}^{2+}$ transients in a time-dependent manner. Ten- to fourteen-day-old transgenic (P35S::apoaequorin) Arabidopsis seedlings grown in hydroponic culture were inoculated with $P$. syringae pv. tomato (Pst) DC3000 at an optical density at $600 \mathrm{~nm}$ of 0.001 or were mock treated. A, The flg22-triggered $\mathrm{Ca}^{2+}$ transients $(1 \mu \mathrm{M})$ were recorded at $12,24,36$, and $48 \mathrm{~h}$ postinoculation (hpi) for $45 \mathrm{~min}$ at 30 -s intervals; flg 22 was added after $2 \mathrm{~min}$. Data represent means and standard deviations of the means of 12 seedlings/treatment. The experiment was repeated three times with similar results. B, The flg22 (1 $\mu \mathrm{M})$-, elf18 $(1 \mu \mathrm{M})-$, chitin $(100 \mu \mathrm{g} / \mathrm{ml})-$, SA $(1 \mathrm{mM})-$, or osmotic shock (700 mM mannitol)-triggered $\mathrm{Ca}^{2+}$ transients were determined at 24 and 48 hpi and total $\mathrm{Ca}^{2+}$ influx following elicitor addition was estimated as area under the curve (AUC). Data represent means and standard errors of the means (SEM) of $\geq 3$ independent biological replicates with 12 seedlings/ replicate and treatment. Lowercase letters indicate statistically significant differences ( $P \leq 0.05$; one-way analysis of variance and Tukey's honestly significant difference post hoc test). mannitol (700 mM), which induces an osmotic shock. Similar to the tested MAMPs, these two substances elicited a transient increase in $\left[\mathrm{Ca}^{2+}\right]_{\text {cyt }}$, which was, however, more irregular in amplitude (especially for SA) and duration (Supplementary Fig. S3). Notably, neither the SA- nor the mannitol-induced $\mathrm{Ca}^{2+}$ response was markedly reduced in the presence of $P$. syringae pv. tomato DC3000 at 24 or 48 hpi under our experimental conditions (Fig. 1B). Taken together, these findings suggest that strain DC3000 is able to attenuate strongly and specifically MAMP-induced $\mathrm{Ca}^{2+}$ signatures during the course of infection. In the following work, we concentrated on flg22 as a wellcharacterized and widely used MAMP for further experiments and 48 hpi as a representative time point.

Thus far, all experiments described above were conducted with hydroponically grown Arabidopsis seedlings. To find out whether our findings are also of relevance in the context of intact soil-grown plants, we performed an assay similar to that described above with leaf discs derived from 5-week-old transgenic Col-0 (P35S::apoaequorin) plants. Leaf discs were placed in 96-well plates and infected with $P$. syringae pv. tomato DC3000 bacteria prior to a flg22 stimulus and recording of the $\mathrm{Ca}^{2+}$ response. Similar to the hydroponic culture system, leaf discs showed a reduced flg22-triggered $\mathrm{Ca}^{2+}$ signature. However, in contrast to the hydroponic system, (nearly) full suppression of the flg22-induced $\mathrm{Ca}^{2+}$ transient was already reached at 24 hpi (Fig. 2A and B). Influx of $\mathrm{Ca}^{2+}$ from external and internal stores into the cytosol is a well-known immediate-early response of plant cells upon MAMP perception (Blume et al. 2000; Jeworutzki et al. 2010; Lecourieux et al. 2006). To explore whether immune responses downstream of cytosolic $\mathrm{Ca}^{2+}$ influx are also affected by the suppressive activity of strain DC3000 bacteria, we analyzed the flg22-induced generation of reactive oxygen species (ROS) and the flg22-triggered transcript accumulation of the prototypical defense marker gene, FLAGELLIN-RESPONSIVE KINASE 1 (FRK1). We noted that the formation of flg22-triggered ROS was fully abolished subsequent to strain DC3000 infection, again regardless of the time point (24 or 48 hpi) (Fig. 2C and D). By contrast, FRK1 mRNA abundance showed a gradual decline, with reduced transcript levels (approximately 50\% compared with $0 \mathrm{hpi}$ ) at 24 hpi and a nearcomplete absence of FRK1 transcripts at 48 hpi (Fig. 2E; Supplementary Fig. S4). The latter findings rule out the possibility that the suppressive effect seen at the level of $\mathrm{Ca}^{2+}$ influx is an artifact of the transgenic aequorin reporter system.

To assess whether the ability to inhibit a MAMP-induced $\mathrm{Ca}^{2+}$ signature is restricted to $P$. syringae pv. tomato DC3000, we next analyzed a broader panel of microorganisms in our assay conditions, which covered pathogenic, nonpathogenic, and beneficial species. This selection included baker's yeast (Saccharomyces cerevisiae) as a fungal representative, a gram-positive bacterium (Bacillus subtilis), and six gram-negative bacteria (Agrobacterium tumefaciens, Burkholderia plantarii, Escherichia coli, P. fluorescens, $P$. putida, and Xanthomonas campestris) (Table 1). Of these, most are known to be associated with plants as either pathogens ( $A$. tumefaciens, $B$. plantarii, and $X$. campestris), plant growthpromoting bacteria (Bacillus subtilis, P. fluorescens, and P. putida), or a sporadic colonizer of ripe fruits ( $S$. cerevisiae) (Goddard and Greig 2015), whereas $E$. coli has no strong established relationship to plant biology. Apart from A. tumefaciens, E. coli, and S. cerevisiae, most of the tested microorganisms were capable of preventing the flg22-triggered $\mathrm{Ca}^{2+}$ response to a considerable extent (Fig. 3A). However, with the exception of Burkholderia plantarii, the suppressive effect of these microorganisms was either delayed or weaker than that of strain DC3000 because, at $48 \mathrm{hpi}$, the AUC was higher in the case of Bacillus subtilis, $P$. fluorescens, $P$. putida, and $X$. campestris (approximately 30 to $40 \%$ of the mock value compared with approximately $10 \%$ for strain DC3000). 
Burkholderia plantarii, however, showed a stronger suppression of the $\mathrm{Ca}^{2+}$ transient than P. syringae pv. tomato (Fig. 3A). In summary, numerous other microorganisms in addition to strain DC3000 are competent to interfere with MAMP-induced $\mathrm{Ca}^{2+}$ signatures.

We next wondered whether the suppressive activity of these microorganisms requires living entities. To address this question, we assessed the ability of heat-treated $\left(95^{\circ} \mathrm{C}, 5 \mathrm{~min}\right)$ microorganisms to interfere with the flg22-induced $\mathrm{Ca}^{2+}$

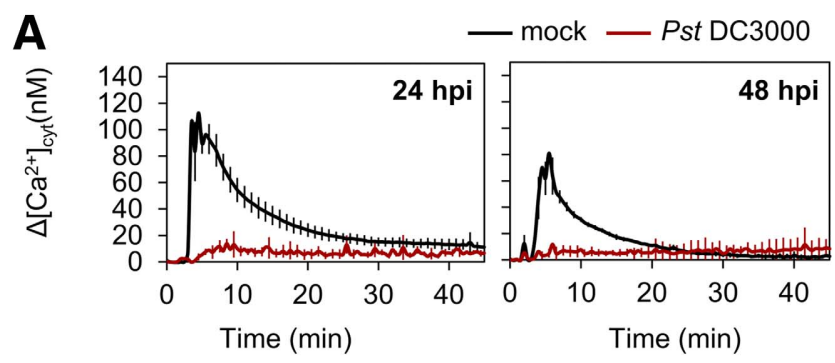

B

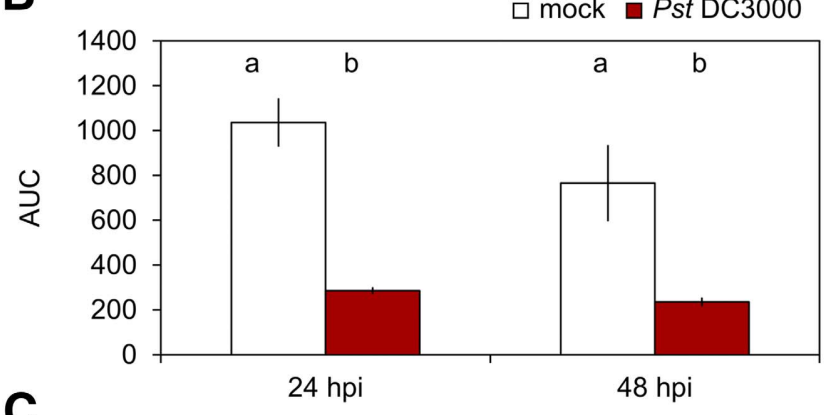

C

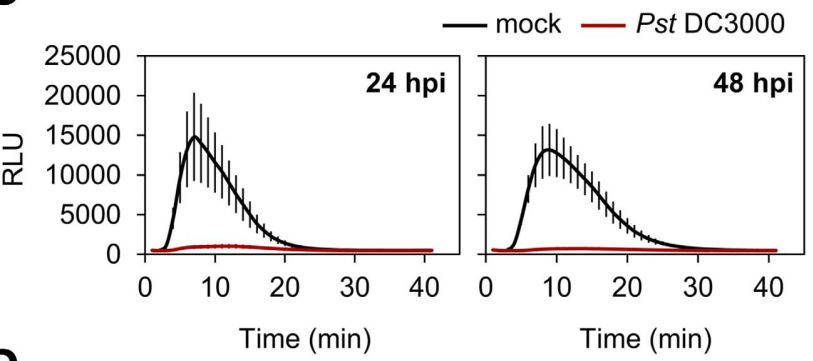

D

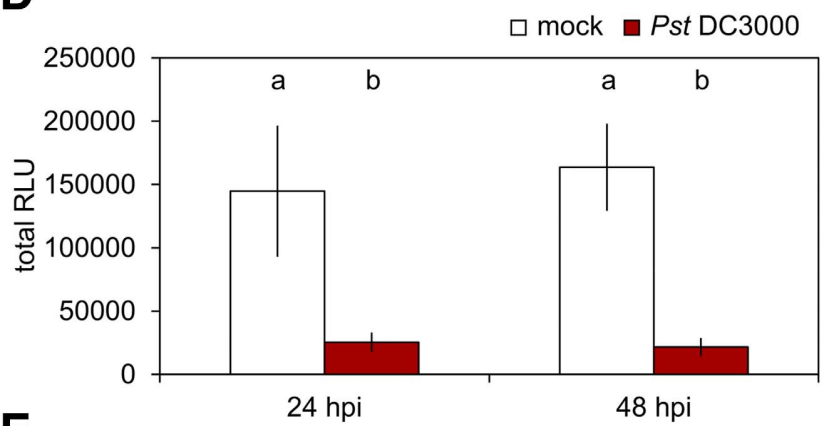

E

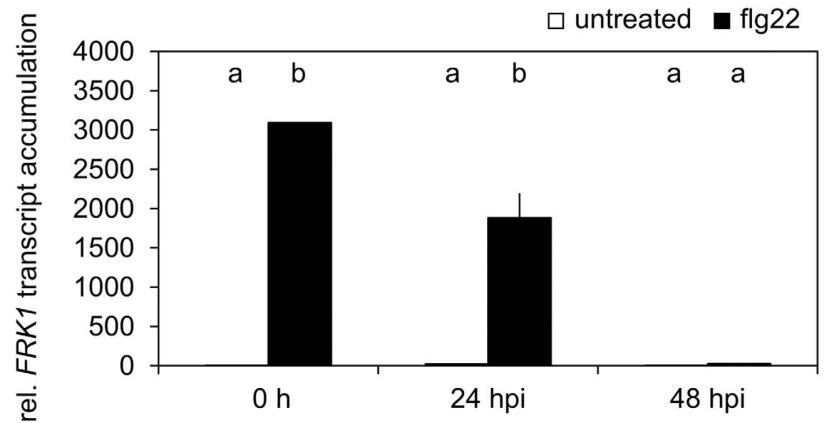

response. Notably, none of the microorganisms that had previously shown statistically significant effects (Fig. 3A) retained the capacity to impede the flg22-triggered $\mathrm{Ca}^{2+}$ signature upon heat inactivation (Fig. 3B). This finding suggests that the critical factors are either temperature sensitive or depend on a living organism.

According to current understanding, secreted effector proteins are considered to be key tools deployed by phytopathogens for host cell manipulation (Büttner 2016; Toruño et al. 2016). The T3SS is believed to be the main device for the delivery of effector proteins in $P$. syringae pv. tomato DC3000 (Guo et al. 2009). To find out whether the observed reduction of $\Delta\left[\mathrm{Ca}^{2+}\right]_{\mathrm{cyt}}$ was dependent on the T3SS, we performed the above-described assay with strain DC3000 $\Delta h r c C$ and $\Delta h r p A$ mutants, which are defective in essential components of the T3SS (Roine et al. 1997; Yuan and He 1996). The two independent mutants behaved similarly and showed a reduction of the $\mathrm{Ca}^{2+}$ response to approximately 40 and $60 \%$ AUC (Fig. 4A), indicating that the suppressive effect is associated, in part, with a functional T3SS. We obtained similar results with the $\Delta h r p L$ mutant, which lacks the alternative $\sigma$ factor $\operatorname{HrpL}$, controlling the expression of more than 70 virulence-associated genes, including most of the T3SS genes (Lam et al. 2014) (Fig. 4A).

Because we found the T3SS to be partially required for the suppression of the MAMP-triggered $\mathrm{Ca}^{2+}$ transient by $P$. syringae pv. tomato DC3000 bacteria, we wondered whether we could identify one or more known effector proteins that may mediate this suppressive effect. We first focused on deletion mutants of effectors AvrPto and AvrPtoB, which are known to interfere with flg22-induced, FLS2-mediated immune responses in Arabidopsis by binding to PRRs, including FLS2 (AvrPto) (Xiang et al. 2008), or by tagging FLS2 with ubiquitin for proteasomal degradation (AvrPtoB) (Göhre et al. 2008). The deletion mutants $\triangle a v r P t o$ and $\triangle a v r P t o B$ as well as the $\triangle a v r P t o$

Fig. 2. Pseudomonas syringae pv. tomato DC3000 attenuates flg22triggered $\mathrm{Ca}^{2+}$ transients and reactive oxygen species (ROS) accumulation in soil-grown adult Arabidopsis leaves and FRK1 expression in seedlings. $\mathbf{A}$ and $\mathbf{B}$, The flg22 $(1 \mu \mathrm{M})$-triggered $\mathrm{Ca}^{2+}$ transients of leaf discs from 5-week-old transgenic (P35S::apoaequorin) Arabidopsis plants were determined 24 or $48 \mathrm{~h}$ after mock treatment or after $P$. syringae pv. tomato DC3000 inoculation (optical density at $600 \mathrm{~nm}\left[\mathrm{OD}_{600}\right]=0.001$ ). $\mathbf{A}, \mathrm{Ca}^{2+}$ influx was recorded for $45 \mathrm{~min}$ at 30 -s intervals; flg22 was added after 2 min. Data represent means and standard deviations of the means (SDM) of $\geq 6$ leaf discs/treatment. The experiment was repeated four times with similar results. B, Total $\mathrm{Ca}^{2+}$ influx after flg22 addition was estimated as area under the curve (AUC). Data represent means and standard error of the mean (SEM) of four independent biological replicates with 6 leaf discs/replicate and treatment. C and D, The flg22 (1 $\mu \mathrm{M})$-triggered ROS accumulation of leaf discs from 6- to 8-week-old Arabidopsis plants was recorded as relative light units (RLU) in a luminol-based assay at 24 or $48 \mathrm{~h}$ after mock treatment or after strain DC3000 inoculation $\left(\mathrm{OD}_{600}=\right.$ 0.001). C, ROS accumulation was recorded for $45 \mathrm{~min}$ at 30 -s intervals; flg22 was added after 2 min. Data represent means and SDM of $\geq 9$ leaf discs/treatment. The experiment was repeated four times with similar results. D, Total ROS accumulation after flg22 addition was estimated as AUC of experiments shown in C. Data represent means and SEM of three independent biological replicates with $\geq 9$ leaf discs/replicate and treatment. E, FRK1 transcript accumulation of either untreated or flg22 $(1 \mu \mathrm{M})$-treated 10-day-old hydroponically grown Arabidopsis seedlings prior to $(0 \mathrm{~h})$ or after (24 and $48 \mathrm{~h}$ postinoculation [hpi]) inoculation with strain DC3000 $\left(\mathrm{OD}_{600}=0.001\right)$ was quantified by quantitative reverse-transcription polymerase chain reaction. Seedlings were harvested for RNA extraction at $60 \mathrm{~min}$ after addition of flg22. Shown values were normalized to the mRNA abundance of the reference gene At4g26420 and relativized to the untreated sample at 0 hpi. Data represent means and SEM of two independent biological replicates with 10 seedlings/replicate and treatment. Lowercase letters indicate statistically significant differences $(P \leq 0.05$; one-way analysis of variance and Tukey's honestly significant difference posthoc test). 
$\triangle a v r P t o B$ double mutant showed a similar reduction of the flg22induced $\mathrm{Ca}^{2+}$ transient as strain DC3000 wild-type (WT) bacteria, excluding a major contribution of these two effectors to the suppression of the MAMP-triggered $\mathrm{Ca}^{2+}$ signature (Fig. 4B).

We next broadened our approach and took advantage of a collection of effector cluster deletion mutants that each represent a knockout of multiple effector genes (Kvitko et al. 2009). None of the six tested single- or double-cluster mutants $(\Delta I, \Delta I V$, $\Delta C E L, \Delta I X, \Delta X$, and $\Delta I I \Delta X)$ or the $\Delta I \Delta I I \Delta I V \Delta C E L \Delta I X \Delta X$ multicluster mutant which, altogether, is deficient in 18 effector genes, showed altered suppression of the flg22-triggered $\mathrm{Ca}^{2+}$ signature (Fig. 4C). We finally deployed the mutant $\Delta I \Delta I I \Delta I V \Delta C E L \Delta I X \Delta X+10$ which, in addition to the effector genes located in clusters, also lacks 10 additional effector genes located as single-copy genes elsewhere in the bacterial genome. This mutant, which is devoid of the 28 supposedly functional $P$. syringae pv. tomato DC3000 effectors (Cunnac et al. 2011), including AvrPto and AvrPtoB, revealed only a slight relief in the suppressive effect (approximately 20\% AUC instead of approximately 10\% AUC for strain DC3000; difference not statistically significant) (Fig. 4C). In sum, these data suggest that neither individual strain DC3000 effector proteins nor any tested combination thereof conditions the suppression of the flg22-triggered $\mathrm{Ca}^{2+}$ influx.

Because only a partial relief of the prohibitory effect was observed with the T3SS-defective $P$. syringae pv. tomato DC3000 $\Delta h r c C, \Delta h r p A$, and $\Delta h r p L$ mutants (Fig. 4A), we conclude that additional factors must be involved in this phenomenon. In addition to the T3SS, bacteria possess further dedicated systems for the delivery of proteins and possibly other metabolites to the exterior. In total, gram-negative bacteria deploy six major secretion systems (Green and Mecsas 2016). We explored a potential contribution of the twin-arginine translocation (Tat) pathway, which feeds into the type II secretion system (T2SS), by pharmacological inhibition and studied a possible involvement of the type VI secretion system (T6SS) via mutant analysis. Treatment of seedlings with the Tat pathway inhibitors Bay 11-7082 and $N$-phenyl maleimide (Vasil et al. 2012) increased the flg22-induced $\mathrm{Ca}^{2+}$ transient markedly in the absence of bacteria (Supplementary Fig. S5). However, in the presence of strain DC3000, even this elevated response was largely suppressed. Similarly, none of the T6SS mutants ( $\Delta h c p 1, \Delta h c p 2$, $\Delta h c p 1 \quad \Delta h c p 2, \Delta H S I$ I, $\Delta H S I \quad I I$, and $\Delta H S I$ I $\Delta H S I I I)$ (Haapalainen et al. 2012; Sarris et al. 2010) revealed a relief of the strain DC3000-mediated suppression of flg22-induced $\mathrm{Ca}^{2+}$ influx.

Apart from the T3SS, other nonproteinaceous molecules have been attributed to the virulence of $P$. syringae pv. tomato DC3000. Among these is the phytotoxin coronatine, which has been implicated in multiple facets of bacterial pathogenesis (Geng et al. 2014). Therefore, we included the coronatinedeficient strain DC3000 $\Delta c m a$ mutant in our assay and found that it behaved like strain DC3000 WT bacteria. Additional nonproteinaceous factors with a presumed role in the defeat of plant defense are EPSs. Alginates, for example, have been shown to be involved in the chelation of extracellular $\mathrm{Ca}^{2+}$ for the suppression of innate plant immunity (Aslam et al. 2008). Therefore, we tested a range of mutants defective in the production

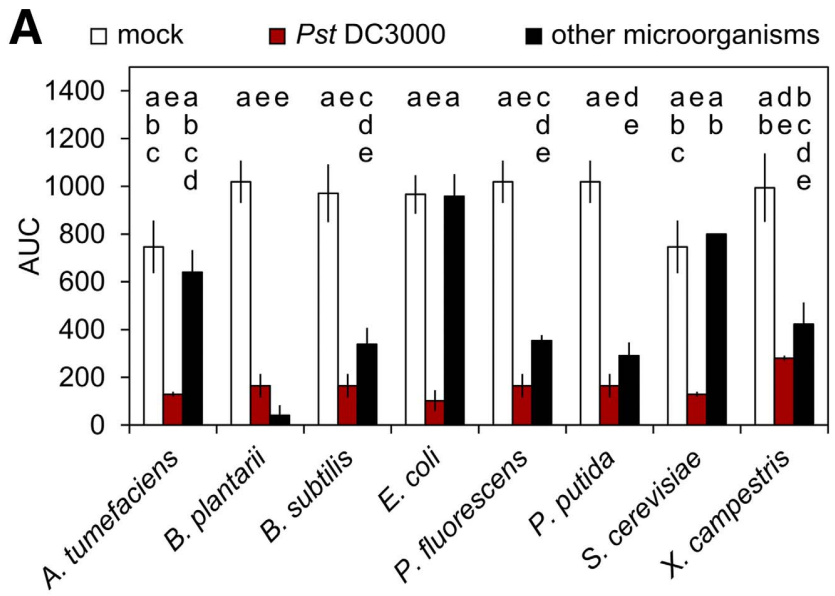

B

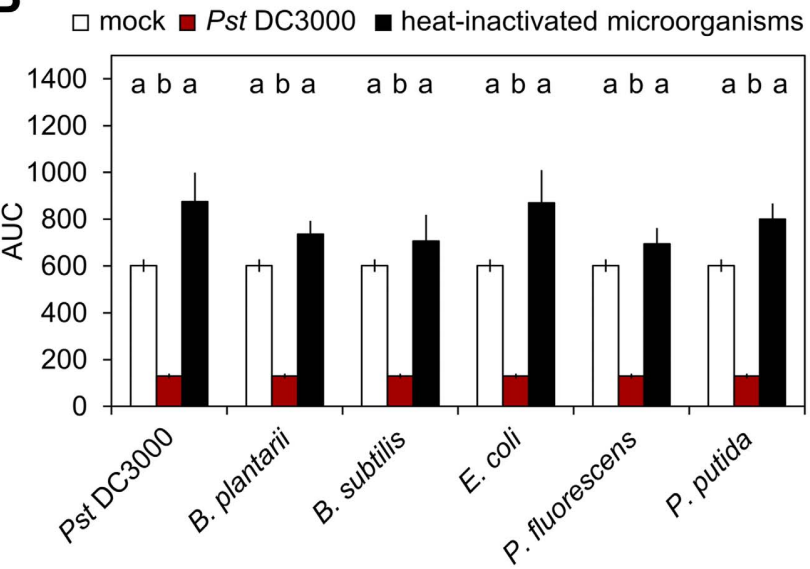

Fig. 3. Ability to attenuate flg22-triggered $\mathrm{Ca}^{2+}$ transients is widespread among plant-associated microorganisms. Ten- to fourteen-day-old transgenic (P35S::apoaequorin) Arabidopsis seedlings were grown in hydroponic culture. The flg22 $(1 \mu \mathrm{M})$-triggered $\mathrm{Ca}^{2+}$ transients were determined at $48 \mathrm{~h}$ postinoculation after mock treatment or inoculation with Pseudomonas syringae pv. tomato DC3000 wild type at an optical density at $600 \mathrm{~nm}=0.001$ and $\mathbf{A}$, the indicated microorganisms (in alphabetical order) or $\mathbf{B}$, heat-inactivated microorganisms that showed statistically significant effects in A. Total $\mathrm{Ca}^{2+}$ influx after flg22 addition was estimated as area under the curve (AUC). Data represent means and standard error of the mean of $\geq 3$ independent biological replicates with 12 seedlings/replicate and treatment. Lowercase letters indicate statistically significant differences $(P \leq 0.05$; one-way analysis of variance and Tukey's honestly significant difference posthoc test).

Table 1. Microorganisms other than Pseudomonas syringae pv. tomato DC3000 used in this study

\begin{tabular}{|c|c|c|}
\hline Microorganisms & Growth conditions $^{a}$ & Reference \\
\hline Xanthomonas campestris pv. vesicatoria $85-10$ & King's B + Rif (50 mg/liter); $28^{\circ} \mathrm{C}$ & Thieme et al. 2005 \\
\hline P. putida KT2440 & $\mathrm{LB}+$ glucose $; 28^{\circ} \mathrm{C}$ & Nelson et al. 2002 \\
\hline P. fluorescens DSM $50090 \mathrm{~T}$ & $\mathrm{LB}+$ glucose $; 28^{\circ} \mathrm{C}$ & DSMZ catalog number 50090 \\
\hline Bacillus subtilis DSM 347 & $\mathrm{LB}+$ glucose $; 28^{\circ} \mathrm{C}$ & DSMZ catalog number 347 \\
\hline Burkholderia plantarii DSM 9509 & $\mathrm{LB}+$ glucose $30^{\circ} \mathrm{C}$ & DSMZ catalog number 9509 \\
\hline Escherichia coli $\mathrm{DH} 5 \alpha$ & $\mathrm{LB} ; 37^{\circ} \mathrm{C}$ & Taylor et al. 1993 \\
\hline Agrobacterium tumefaciens GV3101 pMP90RK & $\mathrm{DYT}+$ Rif (100 mg/liter), $\mathrm{Km}, \mathrm{Gm} ; 28^{\circ} \mathrm{C}$ & Koncz and Schell 1986 \\
\hline Saccharomyces cerevisiae EBY100 & $\mathrm{YEB} ; 28^{\circ} \mathrm{C}$ & Thermo Fisher Scientific, Dreieich, Germany \\
\hline
\end{tabular}

${ }^{\mathrm{a}}$ Rif $=$ rifampicin at $50 \mathrm{or} 100 \mathrm{mg} /$ liter, $\mathrm{Km}=$ kanamycin at $50 \mathrm{mg} /$ liter, and $\mathrm{Gm}=$ gentamycin at $25 \mathrm{mg} /$ liter. LB $=$ lysogeny broth, DYT $=$ double yeast tryptone medium, and YEB = yeast extract broth. 
of various EPS molecules. These included $\triangle a \lg D$ (Aslam et al. 2008) and $\Delta a \lg G / X$ (Jain et al. 2003) mutants, a $\Delta p s l D / E$ mutant (Byrd et al. 2009), a $\Delta w s s B / C$ mutant (Spiers et al. 2002; Gal et al. 2003), as well as some double mutants and a $\Delta a \lg G / X \Delta p s l D / E$ $\triangle w s s B / C$ triple mutant. These mutants lack alginates $(\triangle a l g D$ and $\Delta \operatorname{alg} G / X)$; do not produce a polysaccharide consisting of a repeated pentasaccharide containing D-mannose, D-glucose, and L-rhamnose $(\Delta p s l D / E)$; or are deficient in acetylated cellulose polymer production $(\Delta w s s B / C)$. All tested single and double mutants, as well as the $\Delta a l g G / X \Delta p s l D / E \Delta w s s B / C$ triple mutant, retained full suppression of the flg22-induced $\mathrm{Ca}^{2+}$ response.

An explanation for the absence of any MAMP-triggered $\mathrm{Ca}^{2+}$ signature and further downstream immune responses such as ROS formation and defense gene activation would be the pathogen-induced reduction or membrane depletion of host PRRs such as FLS2, which are indispensable to initiate intracellular defense signaling, including $\mathrm{Ca}^{2+}$ signatures. To

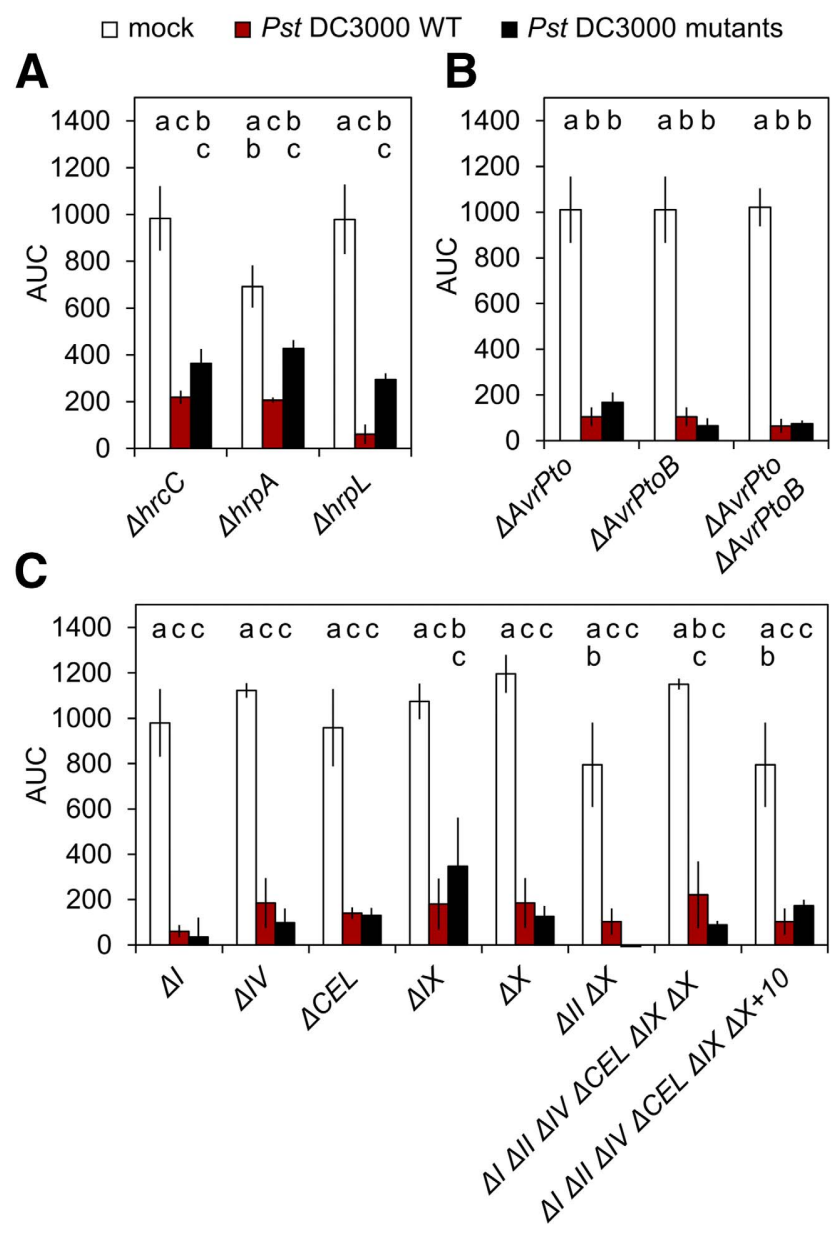

Fig. 4. Loss of the type III secretion system (T3SS); however, neither single nor multiple T3SS effectors deletions impair Pseudomonas syringae pv. tomato DC3000-mediated attenuation of flg22-triggered $\mathrm{Ca}^{2+}$ transients. Ten- to fourteen-day-old transgenic (P35S::apoaequorin) Arabidopsis seedlings were grown in hydroponic culture. The flg22 $(1 \mu \mathrm{M})$-triggered $\mathrm{Ca}^{2+}$ transients were determined at $48 \mathrm{~h}$ postinoculation after mock treatment or inoculation with an optical density at $600 \mathrm{~nm}=0.001$ of $\mathbf{A}$, strain DC3000 wild type or the T3SS-deficient mutants $\triangle h r c C, \triangle h r p A$, and $\triangle h r p L ; \mathbf{B}$, the T3SS effector mutants $\triangle A v r P t o, \triangle A v r P t o B$, and $\triangle A v r P$ to $\triangle A v r P t o B$; or $\mathbf{C}$, deletions of T3SS effector clusters. Total $\mathrm{Ca}^{2+}$ influx after flg22 addition was estimated as area under the curve (AUC). Data represent means and standard error of the mean of $\geq 3$ independent biological replicates with 12 seedlings/replicate and treatment. Lowercase letters indicate statistically significant differences ( $P \leq 0.05$; one-way analysis of variance and Tukey's honestly significant difference posthoc test). test whether proliferation of $P$. syringae pv. tomato DC3000 correlates with a depletion of the cellular FLS2 pool, we performed an immunoblot analysis in the course of bacterial infection of hydroponically grown seedlings. This experiment revealed no reduction and even possibly a slight increase in total FLS2 levels in Col-0 (P35S::apoaequorin) seedlings at 24 and 48 hpi in comparison with either untreated seedlings or seedlings at 0 hpi (Fig. 5A). Confocal imaging further indicated that abundance of membrane-associated FLS2::green fluorescent protein (GFP) fluorescence remained largely unaltered at $48 \mathrm{hpi}$ in either WT strain DC3000 or flagella-deficient strain DC3000 mutants (Supplementary Fig. S6). These findings suggest that degradation or intracellular sequestration of FLS2 is unlikely to be the primary reason for the attenuated MAMP-triggered $\mathrm{Ca}^{2+}$ pattern.

Another possible explanation for the suppressed MAMPinduced $\mathrm{Ca}^{2+}$ response would be a desensitization of host PRRs by MAMPs inadvertently released by the bacterial pathogen during

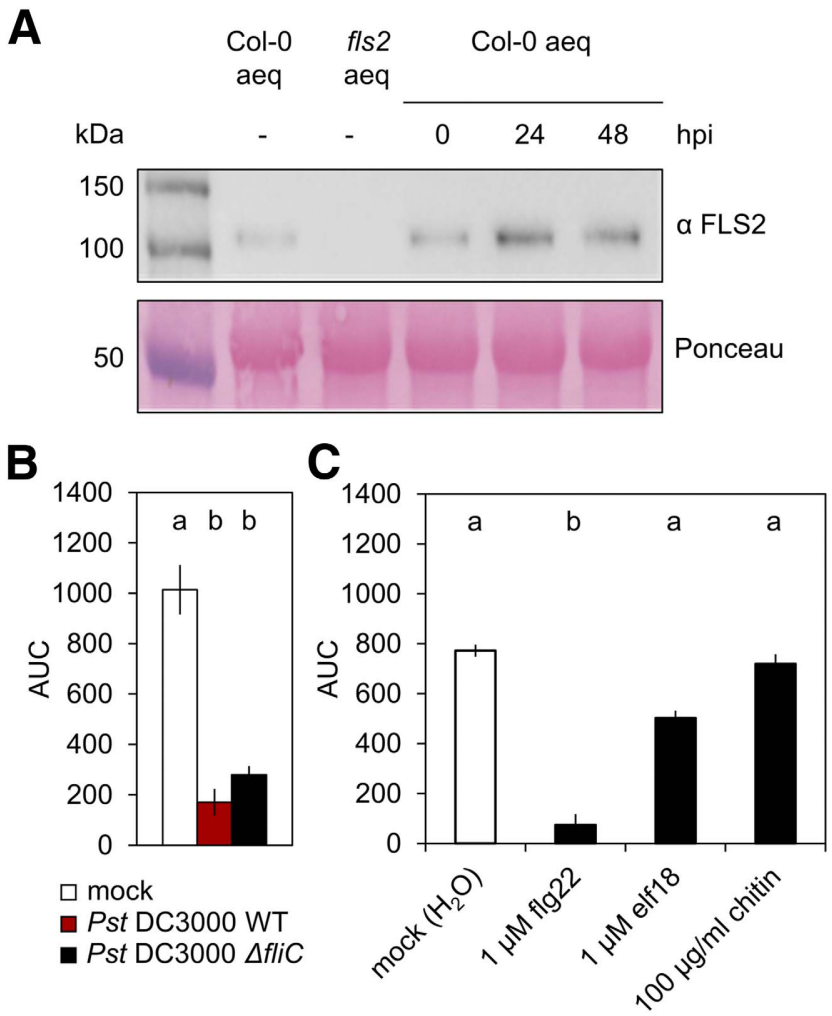

Fig. 5. FLS2 desensitization may contribute to the Pseudomonas syringae pv. tomato DC3000-mediated attenuation of flg22-triggered $\mathrm{Ca}^{2+}$ transients. Ten- to fourteen-day-old transgenic (P35S::apoaequorin) Arabidopsis wild-type (WT) (Col-0) or $f l s 2$ seedlings were grown in hydroponic culture. A, In all, 24 seedlings were sampled immediately $(0 \mathrm{~h})$ or at 24 and $48 \mathrm{~h}$ postinoculation (hpi) with strain DC3000 (optical density at $600 \mathrm{~nm}$ $\left.\left[\mathrm{OD}_{600}\right]=0.001\right)$. FLS2 protein abundance was determined by immunoblot analysis with $\alpha$ FLS2 antibodies. Ponceau staining served as a loading control. A second independent replicate showed similar results. B, The flg22 (1 $\mu \mathrm{M})$-triggered $\mathrm{Ca}^{2+}$ transients were determined at 48 hpi after mock treatment or inoculation $\left(\mathrm{OD}_{600}=0.001\right)$ with strain DC3000 WT and flagellin-deficient strain DC3000 $\Delta$ fliC. Total $\mathrm{Ca}^{2+}$ influx after flg22 addition was estimated as area under the curve (AUC). Data represent means and standard error of the mean (SEM) of seven independent biological replicates with 12 seedlings/replicate and treatment. C, The flg22 $(1 \mu \mathrm{M})$-triggered $\mathrm{Ca}^{2+}$ transients were determined at $48 \mathrm{~h}$ after mock treatment or treatment with $1 \mu \mathrm{M}$ flg22, 1 $\mu \mathrm{M}$ elf18, or chitin at $100 \mu \mathrm{g} / \mathrm{ml}$. Total $\mathrm{Ca}^{2+}$ influx after flg22 addition was estimated as AUC. Data represent means and SEM of three independent biological replicates with 16 seedlings/replicate and treatment. Lowercase letters indicate statistically significant differences $(P \leq 0.05$; one-way analysis of variance and Tukey's honestly significant difference posthoc test). 


\section{A $\square$ mock $\quad$ WT $\triangle$ flic $\Delta c f a \Delta h r c C$ a $\Delta$ flic $\triangle h r c C$ ․ $\Delta f l i c \Delta c f a$ 目 $\Delta c f a \Delta h r c C$}
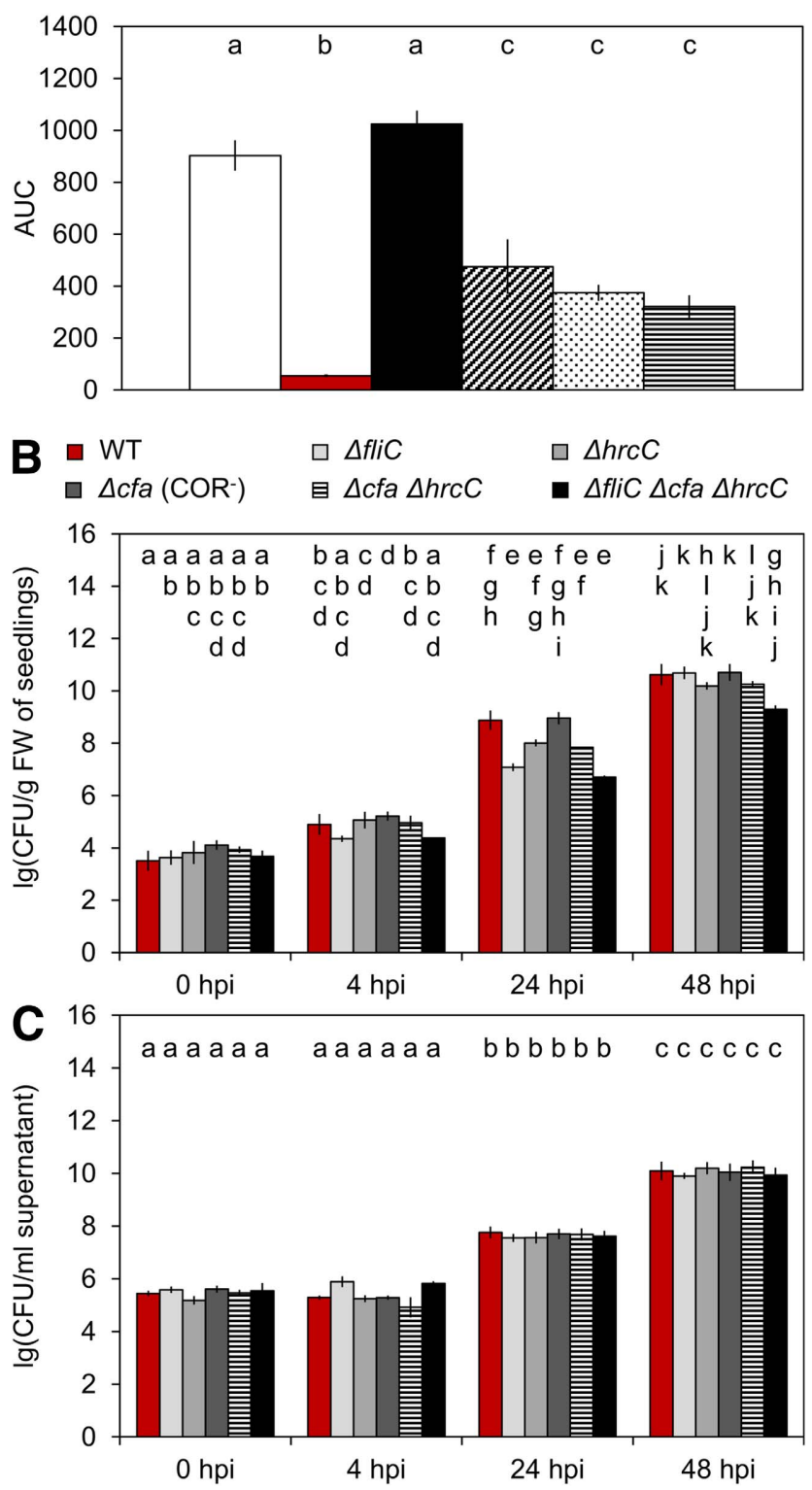

Fig. 6. Coronatine, flagellin, and the type III secretion system (T3SS) cooperatively attenuate flg22-triggered $\mathrm{Ca}^{2+}$ influx. Ten- to fourteen-day-old transgenic (P35S::apoaequorin) Arabidopsis seedlings were grown in hydroponic culture. A, The flg22 $(1 \mu \mathrm{M})$-triggered $\mathrm{Ca}^{2+}$ transients were determined at $48 \mathrm{~h}$ postinoculation (hpi) after mock treatment or inoculation with Pseudomonas syringae pv. tomato DC3000 wild type (WT), strain DC3000 $\Delta c f a \Delta h r c C$ (coronatine-deficient [COR $\left.{ }^{-}\right]$and T3SS-deficient), $\Delta f l i C \Delta c f a$ (flagellin-deficient and $\mathrm{COR}^{-}$), $\Delta f l i C \Delta h r c C$ (flagellinand T3SS-deficient), or $\Delta f l i C \Delta c f a \Delta h r c C$ (flagellin-deficient, $\mathrm{COR}^{-}$, and T3SS-deficient). Total $\mathrm{Ca}^{2+}$ influx after flg22 addition was estimated as area under the curve (AUC). Data represent means and standard error of the mean (SEM) of three independent biological replicates with 12 seedlings/replicate and treatment. B, Seedlings were inoculated with strain DC3000 WT and indicated mutants (optical density at $600 \mathrm{~nm}=0.001$ ). Immediately after inoculation ( $0 \mathrm{hpi}$ ) or after 4, 24, and $48 \mathrm{hpi}$, seedlings were surface sterilized, weighed, and homogenized and bacterial densities of the extracts were determined by evaluating CFU of serial dilutions. C, Culture supernatants of seedlings in B were collected and bacterial densities were determined by evaluating CFU of serial dilutions. Data represent means and SEM of three independent biological replicates with 8 seedlings/replicate and treatment. Lowercase letters indicate statistically significant differences $(P \leq 0.05$; one-way analysis of variance and Tukey's honestly significant difference posthoc test). proliferation. To address this possibility, we performed an experiment with the $P$. syringae pv. tomato DC3000 $\Delta f l i C$ mutant, which is defective in the gene encoding flagellin, an essential building block of bacterial flagella and the natural source of flagellumderived MAMPs during plant colonization. Inoculation with the $\Delta f l i C$ mutant did result in a slight yet not statistically significant relief of suppression of flg22-triggered cytosolic $\mathrm{Ca}^{2+}$ influx (Fig. 5B). However, pretreatment of seedlings with MAMPs at 48 $\mathrm{h}$ prior to a secondary flg22 stimulus led to a severely reduced $\mathrm{Ca}^{2+}$ response in the case of flg22 (10\% of control) and less severe reductions in the case of elf 18 and chitin (65 and $93 \%$ of control, respectively) (Fig. 5C). This finding raises the possibility that the prolonged exposure of MAMPs during bacterial colonization may contribute to the prevention of MAMP-triggered $\mathrm{Ca}^{2+}$ influx.

Because mutants in individual pathogenicity components did not markedly relieve the $P$. syringae pv. tomato DC3000mediated suppression of the flg22-triggered $\mathrm{Ca}^{2+}$ transient (Figs. $4 \mathrm{~A}$ and $5 \mathrm{~B}$ ), we considered combining individual mutations in higher order mutants. The double mutants deficient in T3SS and coronatine $(\Delta c f a \Delta h r C)$, T3SS and flagellin $(\Delta f i C \Delta h r c C)$, and flagellin and coronatine $(\Delta f i C \Delta c f a)$ showed only a partial release of suppression (to approximately 36,53 , and $41 \%$ AUC, respectively) (Fig. 6A). By contrast, inoculation with a $\Delta f i C$ $\Delta c f a \Delta h r c C$ triple mutant resulted in a fully restored $\mathrm{Ca}^{2+}$ response (Fig. 6A). A lack of suppression of the flg22-induced $\mathrm{Ca}^{2+}$ transient by the $\Delta f l i C \Delta c f a \Delta h r c C$ triple mutant correlates with reduced bacterial titers in the seedlings, in particular at 24 hpi (Fig. 6B), whereas bacterial titers in the culture supernatant (and, thus, overall bacterial fitness) were unaffected by the three mutations (Fig. 6C).

\section{DISCUSSION}

In this study, we used a hydroponic culture system in combination with a transgenic Arabidopsis $\mathrm{Ca}^{2+}$ reporter line (Col-0 P35S::apoaequorin) to analyze the molecular prerequisites for effective defense suppression by the phytopathogenic bacterium $P$. syringae pv. tomato DC3000 in the course of the genuine infection process. We focused on the MAMP-induced immediate-early $\mathrm{Ca}^{2+}$ transient as a convenient proxy for the level of bacterial interference with plant immunity. The hydroponic system allows the cultivation of highly uniform host plants, the largely stress-free application of bacteria and MAMPs, and quantitative assessment of the MAMP-triggered response $\left(\mathrm{Ca}^{2+}\right.$ transient). Strain DC3000 infection of Arabidopsis seedlings grown in hydroponic culture resembles bacterial proliferation in soil-grown plants. The aequorin $\mathrm{Ca}^{2+}$ reporter system is well established in the context of plant immunity research and enables accurate measurements of cytoplasmic $\mathrm{Ca}^{2+}$ levels (Kwaaitaal et al. 2011; Ranf et al. 2011; Vatsa et al. 2011). In combination with the 96-well microtiter plate format, this experimental setup permits the measurement of a comparatively high number of plant samples per treatment and the analysis of a large number of conditions and bacterial mutant strains. Thus, the format may also be suitable for studying other aspects of plant-bacteria interactions.

We observed that presence of P. syringae pv. tomato DC3000 caused a suppression of MAMP-induced immune responses within $48 \mathrm{hpi}$ (from $24 \mathrm{hpi}$ onward). This relates to MAMPtriggered $\mathrm{Ca}^{2+}$ transients (Fig. 1A and $\mathrm{B}$ ), the generation of ROS (Fig. 2C and D), and transcript accumulation of defense genes (Fig. 2E). At least with respect to the MAMP-induced $\mathrm{Ca}^{2+}$ signature, this effect is dependent on bacterial titers, is specific for MAMPs (Fig. 1B), and relies on one or more heat-sensitive bacterial factors (Fig. 3B). Together, these data demonstrate the surprising and hitherto undescribed capacity of 
phytopathogenic bacteria to undermine early plant immune signaling in a near-complete manner. Notably, suppression of $\mathrm{Ca}^{2+}$ influx was effective for cell surface immune receptors with external leucine-rich repeat (FLS2 and EFR) and LysM (CERK1) domains (Fig. 1B), which operate either in dependence (FLS2 and EFR) or independently (CERK1) of the BAK1 coreceptor (Chinchilla et al. 2007; Ranf et al. 2011). These findings indicate a broad suppressive activity of strain DC3000, affecting signals transmitted through different types of PRRs and operating via different downstream signaling routes.

At present, there is little published data on the timing of defense suppression in the course of authentic plant-bacteria interactions. Most studies focus on artificial systems such as the heterologous expression or overexpression of individual effectors in plants. However, even under such simplified conditions, it takes a considerable period of time for effects to become detectable. For example, dexamethasone-induced expression of AvrPtoB requires 12 to $24 \mathrm{~h}$ to result in a marked reduction of CERK1 levels in transgenic Arabidopsis plants (Gimenez-Ibanez et al. 2009). Likewise, transient expression of XopJ in Nicotiana benthamiana resulted in a reduction of proteasome activity at 48 hpi (Üstün et al. 2012). It is well conceivable that, in the course of an authentic plant-bacteria interaction, lag times are in a similar order of magnitude. We like to emphasize that we start with a rather low inoculum (OD of 0.001 , corresponding to $10^{3}$ to $10^{4} \mathrm{CFU} / \mathrm{g}$ fresh weight of seedlings) (Fig. 6B) and that bacteria have to enter into plant tissue, assemble the type III secretion apparatus, and deliver effectors that then still need to affect the host machinery, which may require additional time. Given these constraints and the likely asynchronous infection process, we consider it credible that we observe a reduction in MAMP-induced $\mathrm{Ca}^{2+}$ signature from $24 \mathrm{~h}$ onward but not at 12 hpi (Fig. 1A). The reduction in the $\mathrm{Ca}^{2+}$ signature is still partial at $24 \mathrm{hpi}$-possibly because the response to be complete has to be suppressed in all cells of the seedlings, which probably does not happen fast and synchronously, resulting in an intermediate outcome at $24 \mathrm{hpi}$. Realistically, although molecular events related to defense suppression are likely to happen locally before, effects are unlikely to be detectable experimentally at earlier time points at the whole-seedling level.

We were unable to pinpoint further the partial loss of suppressive activity in the $P$. syringae pv. tomato DC3000 $\Delta h r c C$, $\triangle h r p A$, and $\Delta h r p L$ mutants to particular T3SS effector proteins. Individual effector cluster mutants $(\Delta I, \Delta I V, \triangle C E L, \Delta I X$, and $\Delta X)$ as well as the multicluster mutants $\Delta I I \Delta X$ and $\Delta I \Delta I I I V \Delta C E L \Delta I X \Delta X$ or the $\Delta I \Delta I I \Delta I V \Delta C E L \Delta I X \Delta X+10 \mathrm{mu}-$ tant, which is defective in 28 TSS functional effector proteins, failed to phenocopy the partially relieved suppression phenotype of the $\Delta h r c C, \triangle h r p A$, and $\Delta h r p L$ mutants (Fig. $4 \mathrm{~A}$ and C). This finding suggests that likely yet-unidentified proteinaceous effectors or possibly nonproteinaceous effectors such as secondary metabolites exert the suppressive effect via the T3SS. Given that strain DC3000 effectors AvrPto and AvrPtoB were previously reported to target the FLS2 immune receptor (Göhre et al. 2008; Xiang et al. 2008), it was surprising that strain DC3000 mutants defective in AvrPto or AvrPtoB did not show any relief of the suppression of the flg22-triggered $\mathrm{Ca}^{2+}$ transient (Fig. 4B). This result suggests that either additional effectors may target this immune receptor or that the bacterial blockade of $\mathrm{Ca}^{2+}$ influx might happen downstream of MAMP perception.

In principle, suppression of MAMP-triggered $\mathrm{Ca}^{2+}$ transients could be achieved by obstructing the respective MAMP receptors, interfering with cytoplasmic signaling downstream of MAMP receptors, or by impeding the activity of $\mathrm{Ca}^{2+}$ channels.
Given that responses to multiple MAMPs such as flg22, elf18, and chitin are hindered (Fig. 1B), suppression at the level of individual MAMP receptors seems rather unlikely. The molecular events downstream of MAMP receptor activation that lead to the opening of $\mathrm{Ca}^{2+}$ channels remain largely obscure. Similarly, the molecular identity of $\mathrm{Ca}^{2+}$ channels involved in mediating MAMP-triggered $\mathrm{Ca}^{2+}$ influx from the apoplastic space are unknown at present. Results from pharmacological inhibitor experiments point to an involvement of ionotropic glutamate receptor-like channels in this respect (Kwaaitaal et al. 2011; Vatsa et al. 2011). Because $\mathrm{Ca}^{2+}$ transients induced by SA or mannitol remain unaltered by strain DC3000 (Fig. 1B), direct interference with $\mathrm{Ca}^{2+}$ channels also seems unlikely, unless there were MAMP-specific $\mathrm{Ca}^{2+}$ channels that are blocked by bacteria in a very specific manner. In the future, identification of bacterial components that specifically inhibit MAMP-induced $\mathrm{Ca}^{2+}$ influx might pave the way toward identification of the responsible host $\mathrm{Ca}^{2+}$ channels.

Unexpectedly, suppression of the MAMP-induced $\mathrm{Ca}^{2+}$ transient occurred, in part, independently of the T3SS, which is usually considered the key device for bacterial pathogenicity (Deng et al. 2017). Largely apathogenic strain DC3000 $\Delta h r c C$ (Hauck et al. 2003), $\Delta h r p A$ (Roine et al. 1997), and $\Delta h r p L$ (Lam et al. 2014) mutants, which are unable to deliver any T3SS effectors into host cells, were still capable of suppressing the flg22induced $\mathrm{Ca}^{2+}$ transient for the most part (Fig. 4A). Thus, the T3SS is necessary but not sufficient for full defense suppression, suggesting that factors different from the T3SS contribute to this activity. By genetic or pharmacological analysis, we ruled out the individual contribution of EPSs, coronatine, flagellin (Fig. $5 B$ ), the Tat translocation pathway, and the T6SS. However, a triple mutant defective in the T3SS and coronatine biosynthesis and lacking flagellin ( $\Delta f l i \mathrm{Acfa} \Delta h r c C$ ) was unable to prevent flg22-triggered $\mathrm{Ca}^{2+}$ influx (Fig. 6A), indicating that the suppressive activity is likely a combinatorial effect involving multiple bacterial virulence factors. This notion is further corroborated by the fact that each of the tested double mutants ( $\Delta f i C \Delta c f a, \Delta c f a$ $\Delta h r c C$, and $\Delta f i C \Delta h r c C$ ) partially retained the ability to abrogate the flg22-induced $\mathrm{Ca}^{2+}$ signature (Fig. 6A). Thus, it seems as if motility or flagellin exposure $(f i C)$, effector delivery $(h r c C)$, and phytotoxin production $(c f a)$ collectively contribute to the suppressive effect. However, the restored MAMP-induced $\mathrm{Ca}^{2+}$ levels in the case of the $\Delta$ fliC $\Delta c f a \Delta h r c C$ triple mutant correlated with reduced bacterial titers (Fig. 6B). Thus, on the basis of these data, it is impossible to discriminate whether the inability of strain DC3000 to suppress a $\mathrm{Ca}^{2+}$ response results in reduced bacterial proliferation or whether reduced bacterial growth causes a reduction in the ability to interfere with $\mathrm{Ca}^{2+}$ influx in the host.

We discovered that a diverse panel of bacteria has the capacity to exert a level of suppression of flg22-induced $\mathrm{Ca}^{2+}$ influx similar to that of $P$. syringae pv. tomato DC3000 (Fig. 3A). These comprise gram-positive (Bacillus subtilis) and gramnegative (Burkholderia plantarii, P. fluorescens, $P$. putida, and $X$. campestris) bacteria with different lifestyles, including various phytopathogens and plant endophytes. This observation raises the question of whether the respective underlying molecular mechanism might be conserved across these species. Given that the gram-positive bacterium Bacillus subtilis as well as the genome-sequenced strains of $A$. tumefaciens and $P$. putida used in our experiments lack a T3SS (Economou et al. 2006; Nelson et al. 2002; Wood et al. 2001), which partially contributes to the suppression of $\mathrm{Ca}^{2+}$ in strain DC3000 (Fig. $4 \mathrm{~A})$, this is an unlikely scenario. Among gram-positive and gram-negative bacteria, the general secretion $(\mathrm{Sec})$ and Tat secretion pathways are highly conserved (Green and Mecsas 2016) and, thus, could represent common routes for the delivery 
of suppressive molecules. In addition, presence of the T1SS, T2SS, T6SS, and possibly the T5SS is a joint feature of the gram-negative bacteria that showed a suppressive effect in our experiments (Supplementary Table S1). Nevertheless, we cannot rule out the possibility that each bacterial species might exert its own version of defense suppression, using species- or isolate-specific molecular components or pathways (such as, for example, coronatine biosynthesis in the case of strain DC3000).

Microorganisms that failed to suppress the flg22-induced $\mathrm{Ca}^{2+}$ transient comprise the yeast $S$. cerevisiae as well as the gramnegative bacteria A. tumefaciens and E. coli (Fig. 3A). These organisms lack flagellae (S. cerevisiae), have a flagellin version that cannot be perceived by Arabidopsis (A. tumfaciens) (Felix et al. 1999; Gómez-Gómez et al. 1999), or, despite the presence of flagellae, are essentially immobile (E. coli DH5 $\alpha$ laboratory strain used in this study) (Wood et al. 2006). This commonality may hint at FLS2 desensitization or bacterial motility as a common denominator of the ability to suppress the flg22-triggered $\mathrm{Ca}^{2+}$ pattern. However, the $P$. syringae pv. tomato DC3000 $\triangle$ fliC mutant, which lacks flagellae and is rather immotile, largely retained the capacity to interfere with flg22-triggered $\mathrm{Ca}^{2+}$ influx (Fig. 5B). Similarly, crude extracts of different $X$. campestris pathovars were not able to trigger FLS2-dependent medium alkalinization (Felix et al. 1999) but the living bacteria have the ability to interfere with flg22-triggered $\mathrm{Ca}^{2+}$ influx (Fig. 3A). We also did not measure a significant reduction of the FLS2 pool (Fig. 5A) or depletion of FLS2 from the plasma membrane after treatment with bacterial WT and flagellindeficient mutant strains but did observe flg22-provoked desensitization of the flg22-induced $\mathrm{Ca}^{2+}$ pattern (Fig. 5C). Although the latter finding might support the idea of exposed bacterial MAMPs indirectly attenuating plant immune signaling, we do not know whether the MAMP concentrations used in this experiment reflect physiological levels. It is also noteworthy that we observed little if any cross-desensitization of flg22 perception by unrelated MAMPs such as elf18 or chitin (Fig. 5C). Hence, it is difficult to reconcile why the $\Delta f i C$ mutant would retain the ability to attenuate MAMP-induced $\mathrm{Ca}^{2+}$ influx (Fig. 5B). Thus, although flagellin perception or FLS2 desensitization may contribute to the phenomenon of inhibiting the MAMP-triggered $\mathrm{Ca}^{2+}$ signature, these mechanisms are insufficient to explain all findings. Nevertheless, it is conceivable that prolonged MAMP exposition upon plant colonization might support bacterial pathogenesis by desensitizing the host PRR system. Therefore, in summary, we conclude that likely multiple virulence factors (T3SS, coronatine biosynthesis, and presence of flagella), possibly in combination with desensitization of PRRs upon prolonged exposure to bacterial MAMPs, mediate the suppressive effect on the flg22-induced $\mathrm{Ca}^{2+}$ pattern.

\section{MATERIALS AND METHODS}

Plant materials and plant growth conditions.

Arabidopsis thaliana WT (ecotype Col-0), a transgenic apoaequorin-expressing Col-0 line (P35S::apoaequorin) (Knight et al. 1991), and the fls $2 c$ mutant (Nekrasov et al. 2009; Zipfel et al. 2004) were used in this study. For cultivation of seedlings in hydroponic culture, seeds were surface sterilized with $70 \%$ ethanol and then with $100 \%$ ethanol (1 min each) and subsequently dried before distribution for cultivation. Seedlings were grown in white 96-well plates (1 seedling/well; Perkin Elmer, Rodgau, Germany) in $160 \mu \mathrm{l}$ of sterile $1 \times$ Murashige-Skoog (MS) medium supplemented with $0.25 \%$ sucrose under shortday conditions $\left(10 \mathrm{~h}\right.$ light at $22^{\circ} \mathrm{C}$ and $14 \mathrm{~h}$ of darkness at $\left.19^{\circ} \mathrm{C}\right)$. At the age of 10 to 14 days, seedlings were inoculated with microorganisms and used for $\mathrm{Ca}^{2+}$ measurements, RNA extraction, and quantitative reverse-transcription polymerase chain reaction (qRT-PCR) analysis. For growth in soil, Arabidopsis seeds were germinated on wet soil and stratified overnight at $4^{\circ} \mathrm{C}$. Plants were maintained under short-day conditions (10 h of light at $22^{\circ} \mathrm{C}$ and $4 \mathrm{~h}$ of darkness at $19^{\circ} \mathrm{C}$ ) for 5 weeks until usage in the respective experiments.

\section{Phytopathogens and other microorganisms.}

All P. syringae pv. tomato DC3000 strains used in this study (Table 2) were grown at $28^{\circ} \mathrm{C}$ in King's B medium supplemented with suitable antibiotics. Indicated mutations were confirmed by PCR with gene-specific oligonucleotide primers. Instead of genomic DNA, a colony suspension of the strain DC3000 strains prepared in sterile deionized water was used as a template for PCR-based genotyping. Examination of the previously molecularly uncharacterized $\Delta \operatorname{alg} D$ mutant revealed a partial duplication of the $\operatorname{alg} D$ gene, resulting in $\operatorname{alg} D$ dysfunction (see Supplementary Fig. S7 for further details). All microorganisms other than strain DC3000 strains used in this study and the respective growth conditions are given in Table 1.

\section{Trypan blue staining of dead tissue.}

Mock-inoculated or P. syringae pv. tomato DC3000-treated seedlings were stained with trypan blue at $1 \mathrm{mg} / \mathrm{ml}$ in 1:1:1:1 lactic acid-phenol-glycerol-distilled $\mathrm{H}_{2} \mathrm{O}$ for $1 \mathrm{~h}$ and destained in $80 \%$ ethanol, as described previously (Fernández-Bautista et al. 2016)

\section{Generation of $P$. syringae pv. tomato $\mathrm{DC} 3000$ deletion strains.}

The $P$. syringae pv. tomato DC3000 EPS deletion strains (Table 2) were generated via an adaptation of the protocol described elsewhere (Hmelo et al. 2015). Briefly, 500-bp homologous flanking regions to the target genes $w s s B / C$, $p s l D / E$, and $a \lg G / X$ were PCR amplified and ligated individually into the suicide vector pTS1 (Scott et al. 2017). Gene deletion was done by allelic exchange in a two-step homologous recombination process. Strain DC3000 was transformed with the resulting gene deletion vectors by electroporation and cells with successful homologous recombination, leading to chromosomal integration of the plasmid selected on plates containing tetracycline at $12.5 \mu \mathrm{g} / \mathrm{ml}$. Counter selection on $5 \%$ sucrose plates was used to identify cells with a second homologous recombination event resulting in excision of the plasmid and in-frame deletion of the respective genes, leaving 6 to $15 \mathrm{bp}$ between the intact start and stop codons. In all cases, deletion strains were confirmed by PCR and sequencing. Strain DC3000 $f l i C$ was deleted by a similar approach using the pK18mob$s a c B$-derivative allelic exchange vector pCPP5615 (Kvitko et al. 2009). Allelic replacements of $\mathrm{fliC}$ were screened for loss of motility on $0.2 \%$ agar swim plates.

Time-resolved quantification of $\mathrm{Ca}^{2+}$ levels in seedlings.

Col-0 (P35S::apoaequorin) seedlings were grown for 10 to 14 days under short-day conditions (see above) in white 96-well plates ( 1 seed/well; Perkin Elmer) in $1 \times$ MS medium supplemented with $0.25 \%$ sucrose (with vitamins and morpholineethanesulfonic acid [MES]). Then, $100 \mu \mathrm{l}$ of $P$. syringae pv. tomato DC3000 bacteria, other microorganisms (if indicated the microorganisms were heat killed at $95^{\circ} \mathrm{C}$ for 5 min prior to addition to the seedlings), or indicated MAMPs ( $1 \mu \mathrm{M}$ flg22, $1 \mathrm{mM}$ elf 18 , or chitin at $0.1 \mathrm{mg} / \mathrm{ml}$ ) in $0.5 \times \mathrm{MS}$ medium without sucrose were added to the seedlings. The microorganism suspensions were prepared by dilution of an overnight culture to a final theoretical $\mathrm{OD}_{600}$ of 0.001 . Until 1 day prior to the measurement (performed at 24 or $48 \mathrm{hpi}$ ), the seedlings were kept under short-day conditions and then the aequorin substrate coelenterazine $(5 \mathrm{mM}$ 
stock; Biosynth, Staad, Switzerland) dissolved in methanol was added to yield a final concentration of $10 \mu \mathrm{M}$. The seedlings were incubated overnight at room temperature in the dark (due to the photosensitivity of the coelenterazine). Recordings of MAMP-induced $\mathrm{Ca}^{2+}$ signatures were performed as follows. Measurements were accomplished with a Centro XS ${ }^{3}$ LB 960 microplate luminometer (Berthold Technologies, Bad Wildbad, Germany) based on at least $12 \mathrm{WT}$ and 24 mutant seedlings per genotype. Baseline luminescence was measured for four cycles and, subsequently, $25 \mu \mathrm{l}$ of the MAMP solution was injected into $100 \mu \mathrm{l}$ of medium by the luminometer during the fifth cycle, resulting in a final concentration of $1 \mu \mathrm{M}$ flg22, $1 \mu \mathrm{M}$ elf18, or chitin at $0.1 \mathrm{mg} / \mathrm{ml}$ (all elicitors were solved in $0.25 \times \mathrm{MS}$ medium and injected as $5 \times$ stock solutions). Luminescence originating from one seedling was repeatedly recorded for $0.25 \mathrm{~s}$ at 30 -s intervals over a total time of $45 \mathrm{~min}$. Data are given as relative light units (RLUs).

Thereafter, in an independent cycling program, a measurement to determine the total aequorin content was performed. For this purpose $100 \mu \mathrm{l}$ of $2 \mathrm{M} \mathrm{CaCl}_{2}$ in $40 \%$ ethanol was injected during the fifth cycle. In this program, RLUs of each seedling were measured every $65 \mathrm{~s}$ for $0.25 \mathrm{~s}$ over a total time of

Table 2. Pseudomonas syringae pv. tomato DC3000 wild-type and mutant strains used in this study ${ }^{\mathrm{a}}$

\begin{tabular}{|c|c|c|c|c|}
\hline Designation & Relevant characteristics & Additional information & Antibiotics & Reference or source \\
\hline Wild-type & & & Rif & Buell et al. 2003 \\
\hline$\Delta h r c C$ & T3SS deficient & HrcC forms the T3SS outer ring & Rif & $\begin{array}{l}\text { Yuan and He 1996; Peñaloza- } \\
\text { Vázquez et al. } 2000\end{array}$ \\
\hline$\Delta h r p A$ & T3SS deficient & $\begin{array}{l}\text { HrpA is the major component of } \\
\text { the T3SS pilus }\end{array}$ & Rif, Km & Roine et al. 1997 \\
\hline$\Delta h r p L$ & T3SS deficient & $\begin{array}{l}\text { HrpL is an alternative } \sigma \text { factor } \\
\text { regulating T3SS genes }\end{array}$ & Rif & Zwiesler-Vollick et al. 2002 \\
\hline$\Delta f l i C$ & Flagella deficient & $\begin{array}{l}\text { Flagellin }(f l i C) \text { is the flagella } \\
\text { filament structural protein }\end{array}$ & Rif & Kvitko et al. 2009 \\
\hline$\Delta c f a(\Delta c f l-c f a 9)$ & COR deficient & $\begin{array}{l}\text { The } c f a \text { operon codes for } \\
\text { biosynthesis of CFA, one of the } \\
\text { two precursors of COR }\end{array}$ & & Worley et al. 2012 \\
\hline$\Delta c f a \Delta h r c C$ & COR deficient; T3SS deficient & See above & Rif, Sp & Worley et al. 2012 \\
\hline$\Delta f l i C \Delta c f a$ & Flagella deficient; COR deficient & See above & Rif, Gm & This study \\
\hline$\Delta$ fliC $\Delta h r c C$ & Flagella deficient; T3SS deficient & See above & Rif, Gm & This study \\
\hline$\Delta f l i C \Delta c f a \Delta h r c C$ & $\begin{array}{l}\text { Flagella deficient; COR deficient; } \\
\text { T3SS deficient }\end{array}$ & See above & Rif, Sp, Gm & This study \\
\hline$\Delta a v r P t o$ & T3SS effector deficient & $\begin{array}{l}\text { AvrPto inhibits the kinase activity } \\
\text { of FLS } 2 \text { and EFR }\end{array}$ & Rif, Sp & Ronald et al. 1992 \\
\hline$\triangle a v r P t o B$ & T3SS effector deficient & $\begin{array}{l}\text { AvrPtoB is an E3 ubiquitin ligase } \\
\text { that degrades PRRs, including } \\
\text { FLS2 }\end{array}$ & Rif, Km & Abramovitch et al. 2003 \\
\hline$\Delta$ avrPto $\triangle$ avrPtoB & T3SS effector deficient & $\begin{array}{l}\text { AvrPto and AvrPtoB block the } \\
\text { function of PRR complexes }\end{array}$ & Rif, Km, Sp & Lin and Martin 2005 \\
\hline$\Delta c m a A(\Delta c m a D-U)$ & COR deficient & $\begin{array}{l}\text { The } c m a \text { operon codes for } \\
\text { biosynthesis of CMA }\end{array}$ & Rif, Km, Sp & Worley et al. 2012 \\
\hline$\Delta a \lg D$ & Alginate (EPS) deficient & Biosynthesis of EPS alginate & Rif, Km & Aslam et al. 2008 \\
\hline$\Delta w s s B / C$ & $\begin{array}{l}\text { Deficient in an EPS (acetylated } \\
\text { form of cellulose) }\end{array}$ & $\begin{array}{l}w s s B / C \text { encode the cellulose } \\
\text { synthase of the wss operon }\end{array}$ & Rif & This study \\
\hline$\Delta p s l D / E$ & PsI (EPS) deficient & Biosynthesis of Psl & Rif & This study \\
\hline$\Delta a \lg G / X$ & Alginate deficient & Biosynthesis of alginate & Rif & This study \\
\hline$\Delta w s s B / C \Delta p s l D / E$ & Wss and Psl deficient & Biosynthesis of alginate & Rif & This study \\
\hline$\Delta w s s B / C \Delta a \lg G / X$ & Wss and alginate deficient & Biosynthesis of alginate & Rif & This study \\
\hline$\Delta p s l D / E \Delta a l g G / X$ & Psl and alginate deficient & Biosynthesis of alginate & Rif & This study \\
\hline $\begin{array}{l}\Delta w s s B / C \Delta p s l D / E \\
\Delta a l g G / X\end{array}$ & Wss, Psl and alginate deficient & Biosynthesis of alginate & Rif & This study \\
\hline$\Delta \mathrm{I}$ & $\Delta h o p U 1 \Delta h o p F 2$ & T3SS effector cluster deletion & Rif & A. Collmer, unpublished \\
\hline$\Delta \mathrm{IV}$ & $\Delta h o p D 1 \Delta h o p R 1 \Delta h o p Q 1-1$ & T3SS effector cluster deletion & Rif & Wei et al. 2007 \\
\hline$\Delta \mathrm{CEL}(\mathrm{VI})$ & $\Delta$ hopN1 $\triangle$ hopAA1-1 $\triangle$ hopM1 $\triangle a v r E$ & T3SS effector cluster deletion & Rif, Sp & Alfano et al. 2000 \\
\hline$\Delta \mathrm{IX}$ & 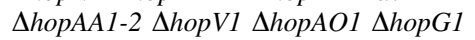 & T3SS effector cluster deletion & Rif & Wei et al. 2007 \\
\hline$\Delta \mathrm{X}$ & 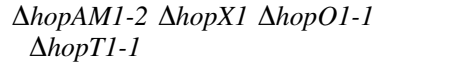 & T3SS effector cluster deletion & Rif & Cunnac et al. 2011 \\
\hline$\Delta \mathrm{II} \Delta \mathrm{X}$ & See above $+\Delta$ hopH1 $\Delta$ hopCl & T3SS effector cluster deletion & Rif & Kvitko et al. 2009 \\
\hline$\Delta \mathrm{I} \Delta \mathrm{II} \Delta \mathrm{IV} \Delta \mathrm{CEL} \Delta \mathrm{IX} \Delta \mathrm{X}$ & See above & T3SS effector cluster deletion & Rif & Kvitko et al. 2009 \\
\hline $\begin{array}{l}\Delta \mathrm{I} \Delta \mathrm{II} \Delta \mathrm{IV} \Delta \mathrm{CEL} \Delta \mathrm{IX} \Delta \mathrm{X} \\
+10(\mathrm{DC} 3000 \mathrm{D} 28 \mathrm{E})\end{array}$ & 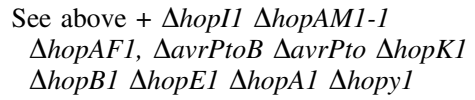 & $\begin{array}{l}\text { T3SS effector cluster deletion } \\
+10 \text { individual effector deletions }\end{array}$ & Rif & Cunnac et al. 2011 \\
\hline$\Delta h c p l$ & $\begin{array}{l}\text { T6SS-dependent secreted protein } \\
\text { deficient }\end{array}$ & $\begin{array}{l}\text { hcpl gene in the HSI-I T6SS } \\
\text { gene cluster }\end{array}$ & Rif & Haapalainen et al. 2012 \\
\hline$\Delta h c p 2$ & $\begin{array}{l}\text { T6SS-dependent secreted protein } \\
\text { deficient }\end{array}$ & $\begin{array}{l}\text { Hcp } 2 \text { is involved in intermicrobial } \\
\text { competition }\end{array}$ & Rif & Haapalainen et al. 2012 \\
\hline$\Delta h c p 1 \Delta h c p 2$ & See above & See above & Rif & Haapalainen et al. 2012 \\
\hline$\Delta H S I-I$ & T6SS deficient & $\begin{array}{l}\text { T6SS chromosomal gene cluster; } \\
\text { Hcp secretion island-I }\end{array}$ & Rif & This study \\
\hline$\Delta H S I-I I$ & T6SS deficient & $\begin{array}{l}\text { T6SS chromosomal gene cluster; } \\
\text { Hcp secretion island-II }\end{array}$ & Rif & This study \\
\hline$\Delta H S I-I \Delta H S I-I I$ & See above & See above & Rif & This study \\
\hline
\end{tabular}

\footnotetext{
${ }^{a}$ Strains were grown in King's B medium or NYG at $28^{\circ} \mathrm{C}$ with respective antibiotics. Km $=$ kanamycin, $\mathrm{Sp}=\mathrm{spectinomycin}$, and Gm $=$ gentamycin. Concentration of all antibiotics was $50 \mathrm{mg} /$ liter. Abbreviations: T3SS $=$ type III secretion system, COR $=$ coronatine, CFA $=$ coronafacic acid, PRR $=$ pattern recognition receptor, $\mathrm{CMA}=$ coronamic acid, EPS = exopolysaccharide, and T6SS = type VI secretion system.
} 
30 min. The $\mathrm{CaCl}_{2}$ /ethanol solution permeated the cell membrane and saturated the aequorin/coelenterazine complexes. The data obtained from this measurement were used to calculate the $\left[\mathrm{Ca}^{2+}\right]$ and as well to normalize for variation due to plant condition and size differences.

Calculation of the $\Delta\left[\mathrm{Ca}^{2+}\right]_{\mathrm{cyt}}$ and the corresponding relative AUC.

$\mathrm{Ca}^{2+}$ concentrations were calculated based on RLUs according to the method of Rentel and Knight (2004). To plot $\Delta\left[\mathrm{Ca}^{2+}\right]$, the average $\left[\mathrm{Ca}^{2+}\right]$ before the injection was subtracted from the $\left[\mathrm{Ca}^{2+}\right]$ at each time point. For the assessment of quantitative differences, the integrals (AUCs) of the curves after the injection peak were calculated (based on at least 12 seedlings/ treatment). The integral of the averaged curve after the injection peak was approximated by summing up the products of the means of two consecutive measurements and the respective measurement intervals (30 s) (Supplementary Fig. S8).

\section{Time-resolved quantification of $\mathrm{Ca}^{2+}$ levels in leaf discs.}

At minimum, six leaf discs (5 $\mathrm{mm}$ in diameter) per sample, measured from 5-week-old transgenic (P35S::apoaequorin) Arabidopsis plants grown in soil under short-day conditions, were pretreated for 24 or $48 \mathrm{~h}$ with $100 \mu \mathrm{l}$ of strain DC3000 (diluted to $\mathrm{OD}_{600}=0.001$ in $0.5 \times$ MS medium without sucrose) in a white 96-well plate (Perkin Elmer). The leaf discs were kept under short-day conditions and, 1 day prior to the measurement, coelenterazine (5 mM stock; Biosynth) dissolved in methanol was added to yield a final concentration of $10 \mu \mathrm{M}$. The leaf discs were incubated in the dark at room temperature overnight. The $\mathrm{Ca}^{2+}$ measurements and calculations were performed as described above for seedlings.

\section{RNA extraction and cDNA synthesis.}

Ten 10-day-old hydroponically grown Col-0 seedlings were treated with $1 \mu \mathrm{M}$ flg22 (in $0.5 \times$ MS medium) or mock treated $(0.5 \times \mathrm{MS}$ medium) prior to (at $0 \mathrm{~h}$ ) or after (at 24 and $48 \mathrm{~h}$ ) inoculation with $P$. syringae pv. tomato DC3000 (diluted to $\mathrm{OD}_{600}=0.001$ in $0.5 \times$ MS medium without sucrose). All samples were taken at $60 \mathrm{~min}$ after MAMP addition and immediately transferred to liquid nitrogen. Total RNA was isolated using the NucleoSpin RNA plus Kit (Macherey-Nagel, Düren, Germany) according to the manufacturer's manual. The RNA samples were stored at $-80^{\circ} \mathrm{C}$ until cDNA synthesis. cDNA was synthesized using the High Capacity RNA-to-cDNA Kit (Applied Biosystems, Weiterstadt, Germany) according to the manufacturer's manual. The cDNA samples were stored at $-20^{\circ} \mathrm{C}$ until qRTPCR analysis. FRK1 (At2g19190) transcript accumulation was quantified with primers 5' -CGGTCAGATTTCAACAGTTGTC-3' (forward primer) and 5'-AATAGCAGGTTGGCCTGTAATC-3' (reverse primer; amplicon size $=142 \mathrm{bp}$ ) using the Bio Rad CFX Connect Real-Time System (Bio-Rad, Munich, Germany). The FRK1 expression level was normalized to the reference gene At4g26410 (forward primer 5' - GAGCTGAAGTGGCTTCCAT GAC-3'; reverse primer 5' -GGTCCGACATACCCATGATCC-3'; amplicon size $=81 \mathrm{bp}$ ), which was previously described to be stably expressed under various biotic stress conditions and encodes an uncharacterized conserved protein (Czechowski et al. 2005). Transcript abundance was calculated according to the comparative cycle threshold method (Pfaffl 2001) and values normalized to time point $0 \mathrm{~h}$ of Col- 0 , set to 1 . Three technical replicates were performed per sample and experiment.

\section{Protein extraction and immunoblot analysis.}

In total, 24 10- to 14-day-old transgenic (P35S::apoaequorin) Col-0 or $f l s 2 c$ (negative control) seedlings were sampled immediately (at $0 \mathrm{~h}$ ) or at 24 and $48 \mathrm{hpi}$ with strain
DC3000 (diluted to $\mathrm{OD}_{600}=0.001$ in $0.5 \times \mathrm{MS}$ medium without sucrose) and frozen in liquid nitrogen. Extraction buffer $(150 \mu \mathrm{l}$ per 24 seedlings; $250 \mathrm{mM}$ sucrose, $50 \mathrm{mM}$ HEPES-KOH [pH 7.5], 5\% glycerol [vol/vol], $0.5 \%$ Triton $\mathrm{X}-100$ [vol/vol], $50 \mathrm{mM} \mathrm{Na}{ }_{4} \mathrm{P}_{2} \mathrm{O}_{7}, 1 \mathrm{mM} \mathrm{Na} 2 \mathrm{MoO}_{4}, 25 \mathrm{mM}$ $\mathrm{NaF}, 2 \mathrm{mM}$ dithiothreitol, and Sigma plant protease inhibitor cocktail [EDTA-free]) was added to the frozen plant material and samples were homogenized with an electrical tissue grinder (Heidolph, Schwabach, Germany). The samples were centrifuged at $21,000 \times g$ for $20 \mathrm{~min}$ at $4^{\circ} \mathrm{C}$. The supernatant $(100 \mu \mathrm{l})$ was transferred to a new reaction tube and the protein concentration was determined using the Bradford reagent Roti-Quant (Roth, Karlsruhe, Germany). Following sodium dodecyl sulfate electrophoresis, proteins were transferred to a BioTrace pure nitrocellulose membrane (PALL Corporation, Dreieich, Germany), which was subsequently probed with a commercial polyclonal anti-FLS2 antiserum (1:5000; Agrisera, Vännäs, Sweden). The membrane was washed and then probed with a polyclonal horseradish-coupled goat antirabbit immunoglobulin G secondary antibody (1:2000; Cell Signaling Technology, Danvers, MA, U.S.A.). The chemiluminescence detection was carried out using the SuperSignal West Femto Maximum Sensitivity Substrate (Thermo Fisher Scientific, Dreieich, Germany) according to the provided instructions in a ChemiDoc imaging system of Bio-Rad. For visualization of equal loading of the protein samples, the membrane was stained with Ponceau S solution from AppliChem (Darmstadt, Germany).

\section{Time-resolved quantification of ROS.}

Leaf discs (5 $\mathrm{mm}$ in diameter) from 6- to 8-week-old Col-0 plants grown in soil under short-day conditions were cut (at least nine leaf discs per sample per measurement) and pretreated for 24 or 48 h with $100 \mu \mathrm{l}$ of strain DC3000 suspension (diluted to $\mathrm{OD}_{600}=0.001$ in $0.5 \times$ MS medium without sucrose) in a white 96-well plate (Perkin Elmer). Until 1 day prior to the measurement, the leaf discs were kept under short-day conditions and then transferred for one night into the dark at room temperature. The next day, the bacterial solution was replaced by $50 \mu \mathrm{l}$ of sterile deionized water and incubated for $30 \mathrm{~min}$ on the bench. To each well, $50 \mu \mathrm{l}$ of $400 \mu \mathrm{M}$ luminol dissolved in dimethyl sulfoxide, peroxidase at $20 \mu \mathrm{g} / \mathrm{ml}$, and $2 \mu \mathrm{M}$ flg22 were added with a repeating pipette (HandyStep; BrandTech Scientific, Essex, UK). The measurement was started $1 \mathrm{~min}$ after addition of the solution in a Centro $\mathrm{XS}^{3}$ LB 960 Microplate Luminometer (Berthold Technologies). The luminescence (RLU) was repeatedly measured for $2 \mathrm{~min} / \mathrm{leaf}$ disc at 60-s intervals over a total time of $60 \mathrm{~min}$.

\section{Determination of bacterial titer in hydroponically grown seedlings and culture supernatants.}

Stably transgenic (P35S::apoaequorin) Arabidopsis seedlings were grown in $1 \times$ MS medium with $0.25 \%$ sucrose, vitamins, and MES under short-day conditions for 10 to 14 days in a 96-well plate. P. syringae pv. tomato DC3000 were grown over night at $28^{\circ} \mathrm{C}$ in liquid $\mathrm{NYG}$ medium (tryptone or peptone at 5 $\mathrm{g} / \mathrm{liter}$, yeast extract at $3 \mathrm{~g} / \mathrm{liter}$, and glycerol at $20 \mathrm{ml} / \mathrm{liter}$; $\mathrm{pH}$ 7) supplemented with rifampicin at $50 \mathrm{mg} / \mathrm{liter}$. Bacteria were diluted in $1 \times$ MS medium without sugar but with vitamins and MES to an $\mathrm{OD}_{600}$ of 0.001 . Then, $75 \mu \mathrm{l}$ of the bacterial suspension of one genotype was added to single seedlings in each of eight wells after removal of the initial medium. Samples of seedlings and culture supernatant were taken immediately (approximately $30 \mathrm{~min}$ ) and 4, 24, and $48 \mathrm{~h}$ after the inoculation. Seedlings of eight wells were sampled and combined, surface sterilized in $70 \%$ ethanol for $30 \mathrm{~s}$, and washed twice in sterile water. The weight of the seedlings was determined 
before they were ground in $100 \mu \mathrm{l}$ of $10 \mathrm{mM} \mathrm{MgCl}$ with a plastic pestle. Supernatants of each of the eight wells $(40 \mu \mathrm{l}$ each) were collected and pooled. The ground seedling suspension or the supernatants $\left(10 \mu \mathrm{l}\right.$ each) and $10 \mu \mathrm{l}$ of $10^{-0}$ to $10^{-3}$ (0 and $4 \mathrm{hpi}), 10^{-3}$ to $10^{-6}$ (24 hpi), or $10^{-5}$ to $10^{-8}$ (48 hpi) dilutions were plated in three technical replicates on NYG agar supplemented with rifampicin at $50 \mathrm{mg} / \mathrm{liter}$. Bacteria were grown at $28^{\circ} \mathrm{C}$ until colonies appeared. CFU were determined relative to the weight of the seedlings or volume of the culture supernatant.

\section{Detection and quantification \\ of membrane-associated FLS2-GFP fluorescence.}

Fourteen-day-old WT and transgenic (PFLS2::FLS2-3xmyc$G F P$ ) (Beck et al. 2012) Arabidopsis seedlings were grown in hydroponic culture and mock treated or inoculated with $75 \mu \mathrm{l}$ of a strain DC3000 WT, $\Delta f l i C$, or $\Delta f l i C \Delta c f a \Delta h r c C$ suspension (diluted to $\mathrm{OD}_{600}=0.001$ ), as described above. At $48 \mathrm{hpi}$, fluorescence (500 to $520 \mathrm{~nm}$ ) of seedlings was recorded with a photo multiplier detector of a Leica SP8 confocal microscope with a $63 \times$ objective. For each genotype and treatment, single z-layer micrographs of two areas of both cotyledons of eight individual seedlings were taken. Autofluorescence was recorded in WT seedlings that did not express FLS2GFP. Quantification of the images was performed with CellProfiler (Lamprecht et al. 2007). The membrane-associated fluorescence was determined by subtraction of chloroplastic from total fluorescence and exclusion of background and vesicle-associated fluorescence. Autofluorescence-subtracted FLS2-GFP membrane-associated fluorescence was subsequently determined by subtraction of average Col-0 membraneassociated fluorescence from average membrane-associated FLS2-GFP fluorescence.

\section{Statistical analysis.}

Quantitative experimental data were tested by Levene's test to confirm homogeneity of variance followed by one-way analysis of variance and Tukey's honestly significant difference posthoc test using R/Bioconductor (Gentleman et al. 2004).

\section{ACKNOWLEDGMENTS}

We thank S. Robatzek (The Sainsbury Laboratory, Norwich, U.K.), R. Wilson Jackson (University of Reading, U.K.), A. Collmer (Cornell University, U.S.A.), and J. Dangl (Chapel Hill, NC, U.S.A.) for providing $P$. syringae pv. tomato DC3000 mutants strains; T. Lahaye (Tübingen University, Germany) and L. Blank (RWTH Aachen University, Germany) for providing additional microorganisms: T. Scott (John Innes Centre, Norwich, UK) for providing the pTS1 vector; and S. Robatzek (The Sainsbury Lab, Norwich, U.K.) for providing the transgenic Arabidopsis PFLS2::FLS2-GFP line.

\section{LITERATURE CITED}

Abramovitch, R. B., Kim, Y. J., Chen, S., Dickman, M. B., and Martin, G. B. 2003. Pseudomonas type III effector AvrPtoB induces plant disease susceptibility by inhibition of host programmed cell death. EMBO J. 22:60-69

Alfano, J. R., Charkowski, A. O., Deng, W. L., Badel, J. L., PetnickiOcwieja, T., van Dijk, K., and Collmer, A. 2000. The Pseudomonas syringae Hrp pathogenicity island has a tripartite mosaic structure composed of a cluster of type III secretion genes bounded by exchangeable effector and conserved effector loci that contribute to parasitic fitness and pathogenicity in plants. Proc. Natl. Acad. Sci. U.S.A. 97:4856-4861.

Aslam, S. N., Erbs, G., Morrissey, K. L., Newman, M. A., Chinchilla, D., Boller, T., Molinaro, A., Jackson, R. W., and Cooper, R. M. 2009. Microbe-associated molecular pattern (MAMP) signatures, synergy, size and charge: Influences on perception or mobility and host defence responses. Mol. Plant Pathol. 10:375-387.
Aslam, S. N., Newman, M. A., Erbs, G., Morrissey, K. L., Chinchilla, D., Boller, T., Jensen, T. T., De Castro, C., Ierano, T., Molinaro, A., Jackson, R. W., Knight, M. R., and Cooper, R. M. 2008. Bacterial polysaccharides suppress induced innate immunity by calcium chelation. Curr. Biol. 18:1078-1083.

Beck, M., Zhou, J., Faulkner, C., MacLean, D., and Robatzek, S. 2012. Spatio-temporal cellular dynamics of the Arabidopsis flagellin receptor reveal activation status-dependent endosomal sorting. Plant Cell 24: 4205-4219.

Bender, C. L., Alarcón-Chaidez, F., and Gross, D. C. 1999. Pseudomonas syringae phytotoxins: Mode of action, regulation, and biosynthesis by peptide and polyketide synthetases. Microbiol. Mol. Biol. Rev. 63:266-292.

Blume, B., Nürnberger, T., Nass, N., and Scheel, D. 2000. Receptormediated increase in cytoplasmic free calcium required for activation of pathogen defense in parsley. Plant Cell 12:1425-1440.

Brooks, D. M., Hernández-Guzmán, G., Kloek, A. P., Alarcón-Chaidez, F., Sreedharan, A., Rangaswamy, V., Peñaloza-Vázquez, A., Bender, C. L., and Kunkel, B. N. 2004. Identification and characterization of a welldefined series of coronatine biosynthetic mutants of Pseudomonas syringae pv. tomato DC3000. Mol. Plant-Microbe Interact. 17:162-174.

Buell, C. R., Joardar, V., Lindeberg, M., Selengut, J., Paulsen, I. T., Gwinn, M. L., Dodson, R. J., Deboy, R. T., Durkin, A. S., Kolonay, J. F., Madupu, R., Daugherty, S., Brinkac, L., Beanan, M. J., Haft, D. H., Nelson, W. C., Davidsen, T., Zafar, N., Zhou, L., Liu, J., Yuan, Q., Khouri, H., Fedorova, N., Tran, B., Russell, D., Berry, K., Utterback, T., Van Aken, S. E., Feldblyum, T. V., D’Ascenzo, M., Deng, W. L., Ramos, A. R., Alfano, J. R., Cartinhour, S., Chatterjee, A. K., Delaney, T. P., Lazarowitz, S. G., Martin, G. B., Schneider, D. J., Tang, X., Bender, C. L., White, O., Fraser, C. M., and Collmer, A. 2003. The complete genome sequence of the Arabidopsis and tomato pathogen Pseudomonas syringae pv. tomato DC3000. Proc. Natl. Acad. Sci. U.S.A. 100:10181-10186.

Büttner, D. 2016. Behind the lines-actions of bacterial type III effector proteins in plant cells. FEMS Microbiol. Rev. 40:894-937.

Byrd, M. S., Sadovskaya, I., Vinogradov, E., Lu, H., Sprinkle, A. B., Richardson, S. H., Ma, L., Ralston, B., Parsek, M. R., Anderson, E. M., Lam, J. S., and Wozniak, D. J. 2009. Genetic and biochemical analyses of the Pseudomonas aeruginosa Psl exopolysaccharide reveal overlapping roles for polysaccharide synthesis enzymes in Psl and LPS production. Mol. Microbiol. 73:622-638.

Chinchilla, D., Zipfel, C., Robatzek, S., Kemmerling, B., Nürnberger, T., Jones, J. D. G., Felix, G., and Boller, T. 2007. A flagellin-induced complex of the receptor FLS2 and BAK1 initiates plant defence. Nature 448:497-500.

Cunnac, S., Chakravarthy, S., Kvitko, B. H., Russell, A. B., Martin, G. B., and Collmer, A. 2011. Genetic disassembly and combinatorial reassembly identify a minimal functional repertoire of type III effectors in Pseudomonas syringae. Proc. Natl. Acad. Sci. U.S.A. 108:2975-2980.

Cunnac, S., Lindeberg, M., and Collmer, A. 2009. Pseudomonas syringae type III secretion system effectors: Repertoires in search of functions. Curr. Opin. Microbiol. 12:53-60. doi.org/10.1016/j.mib.2008.12.003

Cuppels, D. A. 1986. Generation and Characterization of Tn5 Insertion Mutations in Pseudomonas syringae pv. tomato. Appl. Environ. Microbiol. 51:323-327.

Czechowski, T., Stitt, M., Altmann, T., Udvardi, M. K., and Scheible, W. R. 2005. Genome-wide identification and testing of superior reference genes for transcript normalization in Arabidopsis. Plant Physiol. 139:5-17.

Deng, W., Marshall, N. C., Rowland, J. L., McCoy, J. M., Worrall, L. J., Santos, A. S., Strynadka, N. C. J., and Finlay, B. B. 2017. Assembly, structure, function and regulation of type III secretion systems. Nat. Rev. Microbiol. 15:323-337.

Denny, T. P. 1995. Involvement of bacterial polysaccharides in plant pathogenesis. Annu. Rev. Phytopathol. 33:173-197.

de Torres, M., Mansfield, J. W., Grabov, N., Brown, I. R., Ammouneh, H., Tsiamis, G., Forsyth, A., Robatzek, S., Grant, M., and Boch, J. 2006. Pseudomonas syringae effector AvrPtoB suppresses basal defence in Arabidopsis. Plant J. 47:368-382.

Economou, A., Christie, P. J., Fernandez, R. C., Palmer, T., Plano, G. V., and Pugsley, A. P. 2006. Secretion by numbers: Protein traffic in prokaryotes. Mol. Microbiol. 62:308-319.

Erhardt, M., Namba, K., and Hughes, K. T. 2010. Bacterial nanomachines: The flagellum and type III injectisome. Cold Spring Harb. Perspect. Biol. 2:a000299.

Faulkner, C., Petutschnig, E., Benitez-Alfonso, Y., Beck, M., Robatzek, S., Lipka, V., and Maule, A. J. 2013. LYM2-dependent chitin perception limits molecular flux via plasmodesmata. Proc. Natl. Acad. Sci. U.S.A. 110:9166-9170. 
Felix, G., Duran, J. D., Volko, S., and Boller, T. 1999. Plants have a sensitive perception system for the most conserved domain of bacterial flagellin. Plant J. 18:265-276.

Fernández-Bautista, N., Domínguez-Núñez, J., Moreno, M. M., and Berrocal-Lobo, M. 2016. Plant tissue trypan blue staining during phytopathogen infection. Bio Protoc. 6:e2078.

Gal, M., Preston, G. M., Massey, R. C., Spiers, A. J., and Rainey, P. B 2003. Genes encoding a cellulosic polymer contribute toward the ecological success of Pseudomonas fluorescens SBW25 on plant surfaces. Mol. Ecol. 12:3109-3121.

Geng, X., Jin, L., Shimada, M., Kim, M. G., and Mackey, D. 2014. The phytotoxin coronatine is a multifunctional component of the virulence armament of Pseudomonas syringae. Planta 240:1149-1165.

Gentleman, R. C., Carey, V. J., Bates, D. M., Bolstad, B., Dettling, M., Dudoit, S., Ellis, B., Gautier, L., Ge, Y., Gentry, J., Hornik, K., Hothorn, T., Huber, W., Iacus, S., Irizarry, R., Leisch, F., Li, C. Maechler, M., Rossini, A. J., Sawitzki, G., Smith, C., Smyth, G. Tierney, L., Yang, J. Y. H., and Zhang, J. 2004. Bioconductor: Open software development for computational biology and bioinformatics. Genome Biol. 5:R80.

Gimenez-Ibanez, S., Hann, D. R., Ntoukakis, V., Petutschnig, E., Lipka, V., and Rathjen, J. P. 2009. AvrPtoB targets the LysM receptor kinase CERK1 to promote bacterial virulence on plants. Curr. Biol. 19:423-429.

Goddard, M. R., and Greig, D. 2015. Saccharomyces cerevisiae: A nomadic yeast with no niche? FEMS Yeast Res. 15:fov009.

Göhre, V., Spallek, T., Häweker, H., Mersmann, S., Mentzel, T., Boller, T., de Torres, M., Mansfield, J. W., and Robatzek, S. 2008. Plant pattern-recognition receptor FLS2 is directed for degradation by the bacterial ubiquitin ligase AvrPtoB. Curr. Biol. 18:1824-1832.

Gómez-Gómez, L., Felix, G., and Boller, T. 1999. A single locus determines sensitivity to bacterial flagellin in Arabidopsis thaliana. Plant J. $18: 277-284$

Green, E. R., and Mecsas, J. 2016. Bacterial secretion systems: An overview. Pages 215-239 in: Virulence Mechanisms of Bacterial Pathogens, Fifth ed. I. Kudva, N. Cornick, P. Plummer, Q. Zhang, T Nicholson, J. Bannantine, and B. Bellaire, eds. American Society for Microbiology Press, Washington, DC.

Guo, M., Tian, F., Wamboldt, Y., and Alfano, J. R. 2009. The majority of the type III effector inventory of Pseudomonas syringae pv. tomato DC3000 can suppress plant immunity. Mol. Plant-Microbe Interact. 22:1069-1080.

Haapalainen, M., Mosorin, H., Dorati, F., Wu, R.-F., Roine, E., Taira, S., Nissinen, R., Mattinen, L., Jackson, R., Pirhonen, M., and Lin, N.-C. 2012. Hcp2, a secreted protein of the phytopathogen Pseudomonas syringae pv. tomato DC 3000 , is required for fitness for competition against bacteria and yeasts. J. Bacteriol. 194:4810-4822.

Hauck, P., Thilmony, R., and He, S. Y. 2003. A Pseudomonas syringae type III effector suppresses cell wall-based extracellular defense in susceptible Arabidopsis plants. Proc. Natl. Acad. Sci. U.S.A. 100:8577-8582.

Hmelo, L. R., Borlee, B. R., Almblad, H., Love, M. E., Randall, T. E. Tseng, B. S., Lin, C., Irie, Y., Storek, K. M., Yang, J. J., Siehnel, R. J., Howell, P. L., Singh, P. K., Tolker-Nielsen, T., Parsek, M. R., Schweizer, H. P., and Harrison, J. J. 2015. Precision-engineering the Pseudomonas aeruginosa genome with two-step allelic exchange. Nat. Protoc. 10:1820-1841.

Jain, S., Franklin, M. J., Ertesvåg, H., Valla, S., and Ohman, D. E. 2003. The dual roles of AlgG in C-5-epimerization and secretion of alginate polymers in Pseudomonas aeruginosa. Mol. Microbiol. 47:1123-1133.

Janjusevic, R., Abramovitch, R. B., Martin, G. B., and Stebbins, C. E. 2006. A bacterial inhibitor of host programmed cell death defenses is an E3 ubiquitin ligase. Science 311:222-226.

Jeworutzki, E., Roelfsema, M. R. G., Anschütz, U., Krol, E., Elzenga, J. T. M., Felix, G., Boller, T., Hedrich, R., and Becker, D. 2010. Early signaling through the Arabidopsis pattern recognition receptors FLS2 and EFR involves $\mathrm{Ca}^{2+}$-associated opening of plasma membrane anion channels. Plant J. 62:367-378.

Kim, Y. J., Lin, N. C., and Martin, G. B. 2002. Two distinct Pseudomonas effector proteins interact with the Pto kinase and activate plant immunity. Cell 109:589-598.

Knight, M. R., Campbell, A. K., Smith, S. M., and Trewavas, A. J. 1991 Transgenic plant aequorin reports the effects of touch and cold-shock and elicitors on cytoplasmic calcium. Nature 352:524-526.

Koncz, C., and Schell, J. 1986. The promoter of TL-DNA gene 5 controls the tissue-specific expression of chimaeric genes carried by a novel type of Agrobacterium binary vector. Mol. Gen. Genet. 204:383-396.

Kvitko, B. H., Park, D. H., Velásquez, A. C., Wei, C.-F., Russell, A. B., Martin G. B., Schneider, D. J., and Collmer, A. 2009. Deletions in the repertoire of
Pseudomonas syringae pv. tomato DC3000 type III secretion effector genes reveal functional overlap among effectors. PLoS Pathog. 5:e1000388.

Kwaaitaal, M., Huisman, R., Maintz, J., Reinstädler, A., and Panstruga, R 2011. Ionotropic glutamate receptor (iGluR)-like channels mediate MAMPinduced calcium influx in Arabidopsis thaliana. Biochem. J. 440:355-373.

Lam, H. N., Chakravarthy, S., Wei, H.-L., BuiNguyen, H., Stodghill, P. V., Collmer, A., Swingle, B. M., and Cartinhour, S. W. 2014 Global analysis of the HrpL regulon in the plant pathogen Pseudomonas syringae pv. tomato DC3000 reveals new regulon members with diverse functions. PLoS One 9:e106115.

Lamprecht, M. R., Sabatini, D. M., and Carpenter, A. E. 2007. CellProfiler: Free, versatile software for automated biological image analysis. Biotechniques 42:71-75.

Lecourieux, D., Ranjeva, R., and Pugin, A. 2006. Calcium in plant defence-signalling pathways. New Phytol. 171:249-269.

Lin, N.-C., and Martin, G. B. 2005. An avrPtolavrPtoB mutant of Pseudomonas syringae pv. tomato DC3000 does not elicit Pto-mediated resistance and is less virulent on tomato. Mol. Plant-Microbe Interact. 18:43-51.

Lindeberg, M., Stavrinides, J., Chang, J. H., Alfano, J. R., Collmer, A., Dangl, J. L., Greenberg, J. T., Mansfield, J. W., and Guttman, D. S. 2005. Proposed guidelines for a unified nomenclature and phylogenetic analysis of type III Hop effector proteins in the plant pathogen Pseudomonas syringae. Mol. Plant-Microbe Interact. 18:275-282.

Macho, A. P., Zumaquero, A., Ortiz-Martín, I., and Beuzón, C. R. 2007. Competitive index in mixed infections: A sensitive and accurate assay for the genetic analysis of Pseudomonas syringae-plant interactions. Mol. Plant Pathol. 8:437-450.

Melotto, M., Underwood, W., and He, S. Y. 2008. Role of stomata in plant innate immunity and foliar bacterial diseases. Annu. Rev. Phytopathol. 46:101-122.

Melotto, M., Underwood, W., Koczan, J., Nomura, K., and He, S. Y. 2006. Plant stomata function in innate immunity against bacterial invasion. Cell 126:969-980.

Moore, R. A., Starratt, A. N., Ma, S. W., Morris, V. L., and Cuppels, D. A. 1989. Identification of a chromosomal region required for biosynthesis of the phytotoxin coronatine by Pseudomonas syringae pv. tomato. Can. J. Microbiol. 35:910-917.

Nekrasov, V., Li, J., Batoux, M., Roux, M., Chu, Z.-H., Lacombe, S., Rougon, A., Bittel, P., Kiss-Papp, M., Chinchilla, D., van Esse, H. P., Jorda, L., Schwessinger, B., Nicaise, V., Thomma, B. P. H. J., Molina, A., Jones, J. D. G., and Zipfel, C. 2009. Control of the pattern-recognition receptor EFR by an ER protein complex in plant immunity. EMBO J. 28:3428-3438.

Nelson, K. E., Weinel, C., Paulsen, I. T., Dodson, R. J., Hilbert, H., Martins dos Santos, V. A. P., Fouts, D. E., Gill, S. R., Pop, M. Holmes, M., Brinkac, L., Beanan, M., DeBoy, R. T., Daugherty, S., Kolonay, J., Madupu, R., Nelson, W., White, O., Peterson, J., Khouri H., Hance, I., Chris Lee, P., Holtzapple, E., Scanlan, D., Tran, K., Moazzez, A., Utterback, T., Rizzo, M., Lee, K., Kosack, D., Moestl, D., Wedler, H., Lauber, J., Stjepandic, D., Hoheisel, J., Straetz, M., Heim, S., Kiewitz, C., Eisen, J. A., Timmis, K. N., Düsterhöft, A. Tümmler, B., and Fraser, C. M. 2002. Complete genome sequence and comparative analysis of the metabolically versatile Pseudomonas putida KT2440. Environ. Microbiol. 4:799-808.

Peñaloza-Vázquez, A., Preston, G. M., Collmer, A., and Bender, C. L. 2000. Regulatory interactions between the Hrp type III protein secretion system and coronatine biosynthesis in Pseudomonas syringae pv. tomato DC3000. Microbiology 146:2447-2456.

Pfaffl, M. W. 2001. A new mathematical model for relative quantification in real-time RT-PCR. Nucleic Acids Res. 29:e45.

Ranf, S., Eschen-Lippold, L., Pecher, P., Lee, J., and Scheel, D. 2011 Interplay between calcium signalling and early signalling elements during defence responses to microbe- or damage-associated molecular patterns. Plant J. 68:100-113.

Rentel, M. C., and Knight, M. R. 2004. Oxidative stress-induced calcium signaling in Arabidopsis. Plant Physiol. 135:1471-1479.

Roine, E., Wei, W., Yuan, J., Nurmiaho-Lassila, E.-L., Kalkkinen, N., Romantschuk, M., and He, S. Y. 1997. Hrp pilus: An hrp-dependent bacterial surface appendage produced by Pseudomonas syringae pv. tomato DC3000. Proc. Natl. Acad. Sci. U.S.A. 94:3459-3464.

Ronald, P. C., Salmeron, J. M., Carland, F. M., and Staskawicz, B. J. 1992. The cloned avirulence gene avrPto induces disease resistance in tomato cultivars containing the Pto resistance gene. J. Bacteriol. 174:1604-1611.

Sarris, P. F., Skandalis, N., Kokkinidis, M., and Panopoulos, N. J. 2010. In silico analysis reveals multiple putative type VI secretion systems and effector proteins in Pseudomonas syringae pathovars. Mol. Plant Pathol. 11:795-804.

Scofield, S. R., Tobias, C. M., Rathjen, J. P., Chang, J. H., Lavelle, D. T., Michelmore, R. W., and Staskawicz, B. J. 1996. Molecular basis 
of gene-for-gene specificity in bacterial speck disease of tomato. Science 274:2063-2065

Scott, T. A., Heine, D., Qin, Z., and Wilkinson, B. 2017. An L-threonine transaldolase is required for L-threo- $\beta$-hydroxy- $\alpha$-amino acid assembly during obafluorin biosynthesis. Nat. Commun. 8: Article 15935.

Shan, L., He, P., Li, J., Heese, A., Peck, S. C., Nürnberger, T., Martin, G. B., and Sheen, J. 2008. Bacterial effectors target the common signaling partner BAK1 to disrupt multiple MAMP receptor-signaling complexes and impede plant immunity. Cell Host Microbe 4:17-27.

Spiers, A. J., Kahn, S. G., Bohannon, J., Travisano, M., and Rainey, P. B. 2002. Adaptive divergence in experimental populations of Pseudomonas fluorescens. I. Genetic and phenotypic bases of wrinkly spreader fitness. Genetics 161:33-46.

Taylor, R. G., Walker, D. C., and McInnes, R. R. 1993. E. coli host strains significantly affect the quality of small scale plasmid DNA preparations used for sequencing. Nucleic Acids Res. 21:1677-1678.

Thieme, F., Koebnik, R., Bekel, T., Berger, C., Boch, J., Büttner, D., Caldana, C., Gaigalat, L., Goesmann, A., Kay, S., Kirchner, O., Lanz, C., Linke, B., McHardy, A. C., Meyer, F., Mittenhuber, G., Nies, D. H., Niesbach-Klösgen, U., Patschkowski, T., Rückert, C., Rupp, O., Schneiker, S., Schuster, S. C., Vorhölter, F.-J., Weber, E., Pühler, A., Bonas, U., Bartels, D., and Kaiser, O. 2005. Insights into genome plasticity and pathogenicity of the plant pathogenic bacterium Xanthomonas campestris pv. vesicatoria revealed by the complete genome sequence. J. Bacteriol. 187:7254-7266.

Toruño, T. Y., Stergiopoulos, I., and Coaker, G. 2016. Plant-pathogen effectors: Cellular probes interfering with plant defenses in spatial and temporal manners. Annu. Rev. Phytopathol. 54:419-441.

Üstün, S., Müller, P., Palmisano, R., Hensel, M., and Börnke, F. 2012. $\mathrm{SseF}$, a type III effector protein from the mammalian pathogen Salmonella enterica, requires resistance-gene-mediated signalling to activate cell death in the model plant Nicotiana benthamiana. New Phytol. 194:1046-1060

Vasil, M. L., Tomaras, A. P., and Pritchard, A. E. 2012. Identification and evaluation of twin-arginine translocase inhibitors. Antimicrob. Agents Chemother. 56:6223-6234.

Vatsa, P., Chiltz, A., Luini, E., Vandelle, E., Pugin, A., and Roblin, G. 2011. Cytosolic calcium rises and related events in ergosterol-treated Nicotiana cells. Plant Physiol. Biochem. 49:764-773.

Vuong, C., Kocianova, S., Voyich, J. M., Yao, Y., Fischer, E. R., DeLeo, F. R., and Otto, M. 2004. A crucial role for exopolysaccharide modification in bacterial biofilm formation, immune evasion, and virulence. J. Biol. Chem. 279:54881-54886.

Wei, C.-F., Kvitko, B. H., Shimizu, R., Crabill, E., Alfano, J. R., Lin, N.-C., Martin, G. B., Huang, H.-C., and Collmer, A. 2007. A Pseudomonas syringae pv. tomato DC3000 mutant lacking the type III effector HopQ1-1 is able to cause disease in the model plant Nicotiana benthamiana. Plant J. 51:32-46.

Wood, D. W., Setubal, J. C., Kaul, R., Monks, D. E., Kitajima, J. P., Okura, V. K., Zhou, Y., Chen, L., Wood, G. E., Almeida, N. F., Jr., Woo, L., Chen, Y., Paulsen, I. T., Eisen, J. A., Karp, P. D., Bovee, D., Sr., Chapman, P., Clendenning, J., Deatherage, G., Gillet, W., Grant, C., Kutyavin, T., Levy, R., Li, M. J., McClelland, E., Palmieri, A.,
Raymond, C., Rouse, G., Saenphimmachak, C., Wu, Z., Romero, P., Gordon, D., Zhang, S., Yoo, H., Tao, Y., Biddle, P., Jung, M., Krespan, W., Perry, M., Gordon-Kamm, B., Liao, L., Kim, S., Hendrick, C., Zhao, Z. Y., Dolan, M., Chumley, F., Tingey, S. V., Tomb, J. F., Gordon, M. P., Olson, M. V., and Nester, E. W. 2001 The genome of the natural genetic engineer Agrobacterium tumefaciens C58. Science 294:2317-2323.

Wood, T. K., González Barrios, A. F., Herzberg, M., and Lee, J. 2006. Motility influences biofilm architecture in Escherichia coli. Appl. Microbiol. Biotechnol. 72:361-367.

Worley, J. N., Russell, A. B., Wexler, A. G., Bronstein, P. A., Kvitko, B. H., Krasnoff, S. B., Munkvold, K. R., Swingle, B., Gibson, D. M. and Collmer, A. 2012. Pseudomonas syringae pv. tomato DC3000 CmaL (PSPTO4723), a DUF1330 family member, is needed to produce L-allo-isoleucine, a precursor for the phytotoxin coronatine. J. Bacteriol. 195:287-296.

Xiang, T., Zong, N., Zou, Y., Wu, Y., Zhang, J., Xing, W., Li, Y., Tang, X., Zhu, L., Chai, J., and Zhou, J. M. 2008. Pseudomonas syringae effector AvrPto blocks innate immunity by targeting receptor kinases. Curr. Biol. 18:74-80.

Xin, X.-F., and He, S. Y. 2013. Pseudomonas syringae pv. tomato DC3000: A model pathogen for probing disease susceptibility and hormone signaling in plants. Annu. Rev. Phytopathol. 51:473-498.

Yuan, J., and He, S. Y. 1996. The Pseudomonas syringae Hrp regulation and secretion system controls the production and secretion of multiple extracellular proteins. J. Bacteriol. 178:6399-6402.

Zipfel, C., Robatzek, S., Navarro, L., Oakeley, E. J., Jones, J. D. G., Felix, G., and Boller, T. 2004. Bacterial disease resistance in Arabidopsis through flagellin perception. Nature 428:764-767.

Zwiesler-Vollick, J., Plovanich-Jones, A. E., Nomura, K., Bandyopadhyay, S., Joardar, V., Kunkel, B. N., and He, S. Y. 2002. Identification of novel hrp-regulated genes through functional genomic analysis of the Pseudomonas syringae pv. tomato DC3000 genome. Mol. Microbiol. 45:1207-1218.

\section{AUTHOR-RECOMMENDED INTERNET RESOURCES}

Biotechnology and Biological Sciences Research Council: https://bbsrc.ukri.org

Deutsche Forschungsgemeinschaft: http://www.dfg.de

DSMZ catalog number 50090:

https://www.dsmz.de/catalogues/details/culture/dsm-50090.html

DSMZ catalog number 347: https://www.dsmz.de/catalogues/details/culture/dsm-347.html

DSMZ catalog number 9509: https://www.dsmz.de/catalogues/details/culture/DSM-9509.html

Excellence Initiative of the German federal and state governments: http://www.dfg.de/en/research_funding/programmes/excellence_ initiative

Gatsby Charitable Foundation: http://www.gatsby.org.uk

Norwich Research Park: https://www.norwichresearchpark.com

RWTH Aachen University: https://www.rwth-aachen.de

This article was modified on 21 Jan 2022. 
ERRATUM / Volume 32, No. 5, 2019 / MPMI-10-18-0291-R

In the article "Widely Conserved Attenuation of Plant MAMP-Induced Calcium Influx by Bacteria Depends on Multiple Virulence Factors and May Involve Desensitization of Host Pattern Recognition Receptors" by Meltem Lammertz, Hannah Kuhn, Sebastian Pfeilmeier, Jacob Malone, Cyril Zipfel, Mark Kwaaitaal, Nai-Chun Lin, Brian H. Kvitko, and Ralph Panstruga, the Materials and Methods section erroneously stated that the $f l s 2-17$ mutant was used for our experiments. In fact, we used the $f l s 2 c$ mutant (harboring the P35S::apoaequorin transgene) in our study (Fig. 5A).

While the $f l s$ 2-17 mutant is in the genetic background of the Arabidopsis thaliana ecotype Landsberg erecta (La-er) and harbors a point mutation in the kinase domain (G0164R) of the FLS2 protein, the $f l s 2 c$ mutant is a T-DNA insertion null mutant (SAIL_691C4) in the genetic background of the A. thaliana ecotype Col-0. This T-DNA mutant was first described by Zipfel et al. (2004) and later termed $f s 2 c$ due to its genetic background (Col-0) (Nekrasov et al. 2009). We apologize for any potential confusion caused. 